\title{
Osteopathic interns' attitudes toward their education and training
}

\author{
VLADIMIR SHLAPENTOKH, $\mathrm{PhD}$ \\ NEIL O'DONNELL, MA \\ MARY BETH GREY, DO
}

The attitudes of two groups of osteopathic medical interns toward their education are compared. The two groups, referred to as osteopathic ideologists and allopathic ideologists, were selected on the basis of their reported first choice of medical school and internship. The groups differed significantly concerning preparation for and commitment to an osteopathic medical career; adherence to osteopathic tenets; evaluation of quality of education; plans for future training; and career plans. Both groups, however, reported a lack of coherence and integration of osteopathic medical principles and practices in their education. Implications for osteopathic medicine and osteopathic medical education are discussed.

(Key words: Osteopathic medical education, osteopathic student attitudes, osteopathic ideology, allopathic ideology)

Alternative activities exist in all spheres of social life. No mainstream system-whether educational, religious, economic, or politicalis sufficiently complete to satisfy an entire society. Thus, alternative institutions evolve to fill voids left by "traditional" or "mainstream"

From the Department of Community Health Science, Michigan State University (Dr Shlapentokh and $\mathrm{Mr}$ O'Donnell), and Michigan State University-College of Osteopathic Medicine (Dr Grey), East Lansing, Mich:

Reprint requests to Vladimir Shlapentokh, PhD, 547 West Fee Hall, Department of Community Health Science, Michigan State University, East Lansing, MI 48824. systems. Such a process has occurred in healthcare during the past century.

Historically, allopathic medicine has been the mainstream form of healthcare in the United States. However, because allopathic medicine proved insufficient to meet the healthcare needs of all Americans, osteopathic medicine emerged as an alternative form of healthcare. Traditionally, osteopathic physicians (DOs) differ from allopathic physicians (MDs) in that DOs emphasize preventive medicine, the "whole person" approach to the patient, the importance of the musculoskeletal system in overall health, and the importance of family practice medicine. In fact, more than $75 \%$ of DOs provide primary healthcare to Americans, compared with only $25 \%$ of MDs. ${ }^{1}$

As osteopathic medicine became formalized, it simultaneously de-emphasized many traditionally osteopathic principles and practices, such as manipulation. At the same time, the osteopathic medical profession incorporated many traditionally allopathic practices, such as the widespread use of drugs and surgery in treatment. ${ }^{2}$ Thus, a paradox emerged: while developing as an alternative healthcare system, osteopathic medicine surrendered much of that which made it unique and, hence, an alternative approach to healthcare.

With this ideologic change-specifically the melding of allopathic and osteopathic principles and practices - several organizational changes also influenced the evolution of osteopathic medicine. For example, in 1967 the American Medical Association (AMA) began 
allowing graduates of accredited osteopathic medical colleges to enter AMA-approved internship and residency programs. More recently, the American Osteopathic Association (AOA) declared that DOs are no longer required to document their inability to obtain an AOA-approved residency in order to receive AOA approval of their residency training. ${ }^{2}$ (However, all residency programs still require the completion of an AOA-approved internship. ${ }^{3}$ ) Such changes considerably broadened prospective osteopathic physicians' choice of residency programs as well as many of their subsequent professional decisions.

One would expect that such changes would influence students' decisions whether to pursue an osteopathic medical education. Indeed, such changes have been documented over the past several decades. ${ }^{4-6}$

For example, students originally pursued osteopathic medicine as an alternative form of medical practice that offered advantages unavailable through allopathic medicine. Such motivated students still apply to osteopathic medical colleges. However, increasing numbers of students with nontraditional motives are now applying to osteopathic medical schools. Some of these students see osteopathic medicine as an alternative pathway, or "backdoor" into allopathic medicine. The competitive nature of medical school admissions and the increasing similarity between allopathic and osteopathic medicine had contributed to an influx of backdoor students in the past. Even today, applicants are less concerned with philosophy than with becoming physicians. As one student in the current study said, "My first priority was to get into medical school. Philosophy came second."

Just who are these backdoor medical students? Early surveys ${ }^{4,5}$ identified such applicants as persons who applied to osteopathic medical school because of the "close relationship of this field (osteopathic medicine) to another which could not be attained for some reason." Five percent of medical students surveyed in 1967 fit this category. By 1970, the percentage had risen to 15 .

A recent study ${ }^{6}$ defined backdoor students as persons who previously applied to allopathic medical schools but were rejected or applicants who had little knowledge of osteopathic medical principles at the time they applied to an osteopathic medical program. Forty-three percent of the survey respondents met the first criterion, while $28 \%$ met the second.

Eckberg ${ }^{6}$ examined the attitudes of DOs and osteopathic residents in a large metropolitan area in the Midwest and found significant differences between the attitudes of persons who chose osteopathic medicine as an alternative form of medical practice and those who chose osteopathic medicine as an alternative route into a medical career. To our knowledge, however, no comparable data exist regarding the attitudes of osteopathic interns. Our study attempts to fill this void.

\section{Methods}

Data from the current study were drawn from a nationwide survey of all interns training at the 110 AOA-approved training sites (including approved sites at allopathic hospitals) operating in the spring of 1988. (Data collected from senior students surveyed at the same time appears in an as-yet-unpublished article.) The questionnaire was modeled after that used by Mills, ${ }^{4}$ O'Donnell, ${ }^{5}$ and Eckberg. ${ }^{6}$

Of the 1010 interns initially surveyed, 537 (53\%) responded.* Of these respondents, 179 interns fit the criteria established for inclusion in the data base reported here. These criteria are outlined in the Results section.

To assess the representativeness of these data, we conducted a short follow-up survey among a randomly selected sample of 100 interns who had not responded initially. Thirty-one interns $(31 \%)$ responded to the follow-up questionnaire. No significant differences were found between the demographic characteristics of interns who responded to the initial questionnaire and those who responded to the follow-up survey.

Demographically, those interns responding to the initial questionnaire were remarkably similar to the nationwide population of students entering osteopathic medical colleges in 1983. For example, $26 \%$ of the 1983 applicants were women; the same percentage of female interns were found among our

\footnotetext{
${ }^{*}$ Ten percent to $15 \%$ of DOs do not take osteopathic internships, but train instead in allopathic programs during their first postdoctoral year. By definition, these individuals could not participate in our survey. The possible ramifications of their exclusion are examined in the Discussion section.
} 
survey respondents. Likewise, nonwhite applicants and interns accounted for $5 \%$ of both groups. ${ }^{7}$ These demographic similarities, along with the findings from our follow-up survey as well as Eckberg's work, ${ }^{6}$ attest to the external validity of our reported findings.

\section{Results}

\section{Respondents}

Interns were categorized into three groups according to their reported first choice of medical school and internship. These indicators were chosen because they best reflected the respondents' beliefs and goals, independent of pragmatic concerns. The following questions were used to determine first choice of medical school and internship:

When you decided to apply to medical school for the first time, what was your first choice of medical schools?

$\square$ Osteopathic.

Allopathic.

$\square$ I would have attended any that accepted me.

$\square$ Other.

Will your residency training be

Osteopathic?

AOA-approved at an allopathic hospital?

Non-AOA approved?

Military?

\section{Unsure at this point?}

The 127 respondents who answered "osteopathic" to the aforementioned questions made up the first group, identified as Osteopathic Ideologists (OIs).

The second group comprised 52 respondents, identified as Allopathic Ideologists (AIs). $\dagger$ These respondents were currently participating in an osteopathic internship, but had answered the aforementioned questions "allopathic," "AOA-approved at an allopathic hospital," or "non-AOA-approved." $\div$ The remaining 358 respondents in the third group selected any other combination of responses; members in this group were not subjected to further analysis. Most of the results presented heretofore, then, are based on responses from 179 interns. However, in some instances, not every intern answered every question. Therefore, the number in the sample of the population ( $n$ ) in some tables included here vary accordingly.
Because of the selection criteria, less than $50 \%$ of the total number of respondents were designated as either OIs or AIs. We selected these extreme groups to highlight the affinity of interns for either osteopathic or allopathic medicine.

\section{Differences between OIs and AIs}

Because data were categorical, contingency tables and $x^{2}$ tests for equal proportions were employed, using the Statistical Package for the Social Sciences (SPSS-X). For discussion purposes, the items have been sorted into six content-related categories: preparation for and commitment to an osteopathic medical career; adherence to osteopathic tenets; evaluation of quality of education; plans for future training; career plans; and coherence and integration of training. Questions in each category are discussed separately.

\section{Preparation for and commitment to an osteopathic medical career}

Questions in this category reflect the factors that influenced interns, as students, to choose osteopathic medicine; their prior knowledge of the osteopathic philosophy; and the degree to which interns, as students, were committed to receiving an osteopathic medical education.

Differences between OIs and AIs were found on five of the nine possible influences (Table 1). This appears to be a small number; however, three of five significant items clearly reflected an interest (or lack thereof) in osteopathic medicine. Specifically, OIs were significantly more likely to report having been influenced by a preference for the osteopathic philosophy $(P<<.01)$ and by a desire to learn OMT $(P<.02)$ than were AIs. Conversely, AIs were significantly more likely than OIs to report having been influenced by a previous re-

tThe number of interns included in the AI group underestimates their numbers in the population, because $10 \%$ to $15 \%$ of DOs choose allopathic programs for their first postdoctoral year. This choice suggests a preference for allopathic programs similar to that expressed by the AIs in the current study.

†It is assumed that students desiring an osteopathic medical residency as their first choice were able to get one, because the number of AOA-approved residency positions available consistently and significantly outstrips the number filled. 
Table 1

Factors Influencing Interns To Choose To Enter

School of Osteopathic Medicine

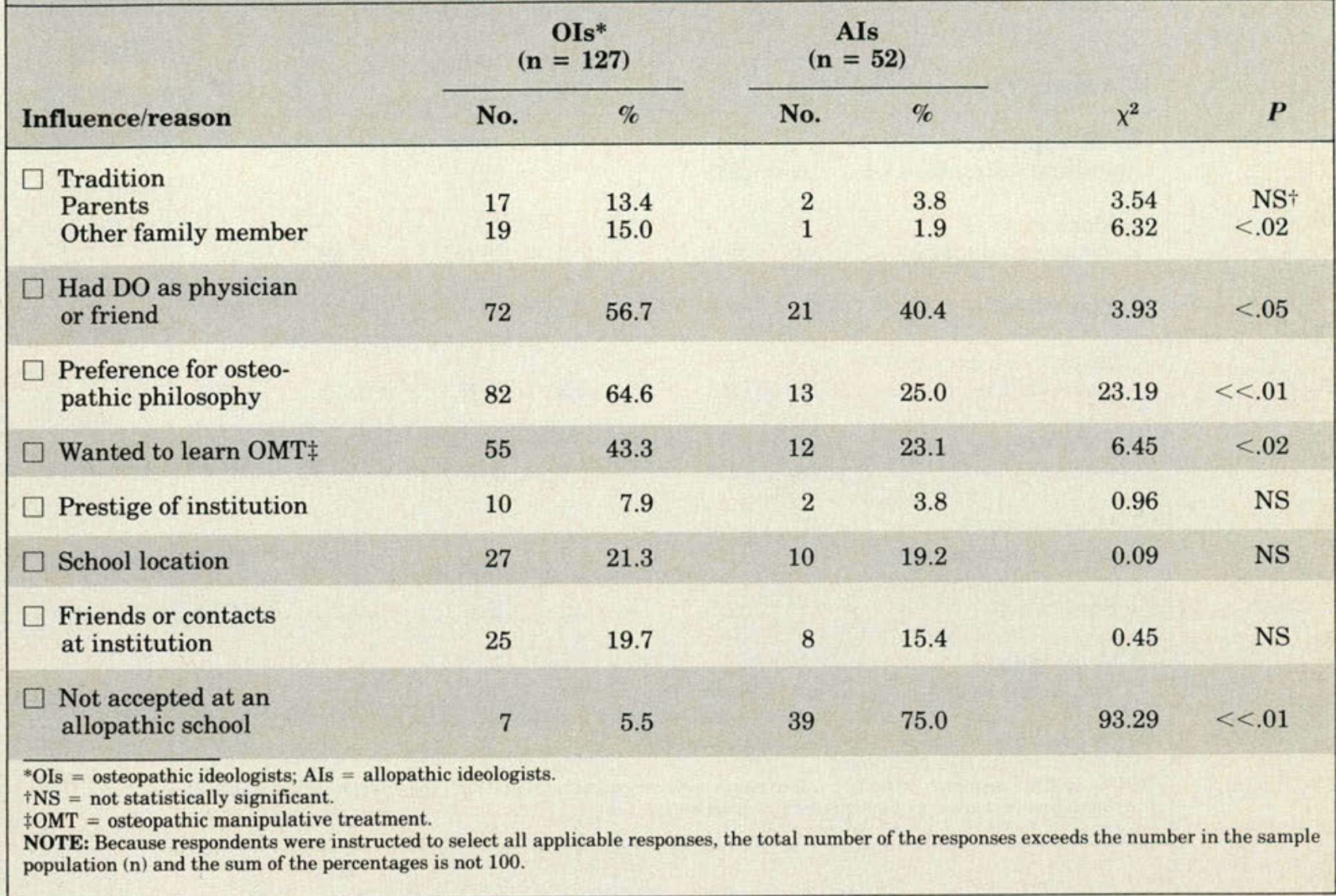

\begin{tabular}{|c|c|c|c|c|c|c|}
\hline \multicolumn{7}{|c|}{$\begin{array}{c}\text { Table } 2 \\
\text { Medical School to Which Students First Applied }\end{array}$} \\
\hline \multirow[b]{2}{*}{ Type of School } & \multicolumn{2}{|c|}{$\begin{array}{c}\text { OIs* } \\
(\mathbf{n}=127)\end{array}$} & \multicolumn{2}{|c|}{$\begin{array}{c}\text { AIss } \\
(n=52)\end{array}$} & \multirow[b]{2}{*}{$x^{2}$} & \multirow[b]{2}{*}{$P$} \\
\hline & No. & $\%$ & No. & $\%$ & & \\
\hline$\square$ Osteopathic & 125 & 98.4 & 50 & 96.2 & 0.87 & NS \\
\hline Allopathic & 48 & 37.8 & 51 & 98.1 & 54.24 & $<<.01$ \\
\hline$\square$ Dental & 2 & 1.6 & 0 & 0.0 & 0.83 & NS \\
\hline \multicolumn{7}{|c|}{$\begin{array}{l}\text { *OIs }=\text { osteopathic ideologists; } \mathrm{AIs}=\text { allopathic ideologists. } \\
\text { +NS }=\text { not statistically significant. } \\
\text { NOTE: Because respondents were instructed to select all applicable responses, the total number of the } \\
\text { responses exceeds the number in the sample population }(\mathrm{n}) \text { and the sum of the percentages is not } 100 .\end{array}$} \\
\hline
\end{tabular}

jection from an allopathic medical school ( $75 \%$ vs $5.5 \%$, respectively).

As might be expected, a significantly greater percentage of the OIs than AIs reported having a fair to very thorough understanding of osteopathic philosophy before ap- plying to osteopathic medical school $(72.2 \%$ vs $39.2 \%$, respectively). In fact, the majority of AIs knew nothing or had only a vague understanding of osteopathic philosophy before applying to osteopathic medical school.

Nearly all of the respondents in both groups 
Table 3

Quality of an Osteopathic Medical Education and Residency Compared With an Allopathic Medical Education and Residency

\begin{tabular}{|c|c|c|c|c|c|c|}
\hline \multirow[b]{2}{*}{ Comparison } & \multicolumn{2}{|c|}{ OIs* } & \multicolumn{2}{|c|}{ AIs } & \multirow[b]{2}{*}{$x^{2}$} & \multirow[b]{2}{*}{$P$} \\
\hline & No. & $\%$ & No. & $\%$ & & \\
\hline $\begin{array}{l}\text { An osteopathic } \\
\text { medical education is: }\end{array}$ & \multicolumn{2}{|c|}{$(n=123)$} & \multicolumn{2}{|c|}{$(n=52)$} & & \\
\hline $\begin{array}{l}\square \text { Much more or } \\
\text { somewhat superior }\end{array}$ & 53 & 43.1 & 13 & 25.0 & 5.09 & $<.02$ \\
\hline$\square$ Equivalent & 60 & 48.8 & 26 & 50.0 & 0.02 & $\mathrm{NS}+$ \\
\hline $\begin{array}{l}\square \text { Much more or } \\
\text { somewhat inferior }\end{array}$ & 10 & 8.1 & 13 & 25.0 & 9.11 & $<.003$ \\
\hline $\begin{array}{l}\text { An osteopathic } \\
\text { residency is: }\end{array}$ & \multicolumn{2}{|c|}{$(n=123)$} & \multicolumn{2}{|c|}{$(n=47)$} & & \\
\hline $\begin{array}{l}\text { Much more or } \\
\text { somewhat superior }\end{array}$ & 14 & 11.4 & 1 & 2.1 & 3.62 & NS \\
\hline$\square$ Equivalent & 65 & 52.8 & 12 & 25.5 & 10.24 & $<.002$ \\
\hline $\begin{array}{l}\text { Much more or } \\
\text { somewhat inferior }\end{array}$ & 44 & 35.8 & 34 & 72.3 & 18.31 & $<<.01$ \\
\hline
\end{tabular}

\section{Table 4}

Osteopathic Interns' Self-Perception Related to Allopathic Peers and Perception of Differences Between Osteopathic and Allopathic Hospitals

\begin{tabular}{|c|c|c|c|c|c|c|}
\hline \multirow[b]{2}{*}{ Perception } & \multicolumn{2}{|c|}{ OIs* } & \multicolumn{2}{|c|}{ AIs } & \multirow[b]{2}{*}{$\chi^{2}$} & \multirow[b]{2}{*}{$P$} \\
\hline & No. & $\%$ & No. & $\%$ & & \\
\hline $\begin{array}{l}\text { Feel inferior to } \\
\text { allopathic students }\end{array}$ & \multicolumn{2}{|c|}{$(n=127)$} & \multirow{2}{*}{\multicolumn{2}{|c|}{$(n=52)$}} & & \\
\hline$\square$ All or some of & & & & & 577 & $<0 ?$ \\
\hline$\square$ Unsure & 21 & 16.5 & $\begin{array}{r}24 \\
4\end{array}$ & $\begin{array}{r}40.2 \\
7.7\end{array}$ & 2.40 & NS + \\
\hline$\square$ Never & 71 & 55.9 & 24 & 46.2 & 1.41 & NS \\
\hline $\begin{array}{l}\text { DO and MD hospitals } \\
\text { differ }\end{array}$ & \multicolumn{2}{|c|}{$(n=125)$} & \multicolumn{2}{|c|}{$(\mathrm{n}=52)$} & & \\
\hline$\square$ Very much & 14 & 11.2 & 6 & 11.5 & 0.00 & NS \\
\hline$\square$ To some degree & 69 & 55.2 & 24 & 46.2 & 1.20 & NS \\
\hline$\square$ Not much at all & 37 & 29.6 & 20 & 38.5 & 1.32 & NS \\
\hline$\square$ Unsure & 5 & 4.0 & 2 & 3.8 & 0.00 & NS \\
\hline
\end{tabular}




\begin{tabular}{|c|c|c|c|c|c|c|}
\hline \multicolumn{7}{|c|}{$\begin{array}{c}\text { Table } 5 \\
\text { Method of Evaluating Residency Program }\end{array}$} \\
\hline \multirow[b]{2}{*}{ Method } & \multicolumn{2}{|c|}{$\begin{array}{c}\text { OIs* } \\
(n=127)\end{array}$} & \multicolumn{2}{|c|}{$\begin{array}{c}\text { AIs } \\
(\mathbf{n}=\mathbf{5 2})\end{array}$} & \multirow[b]{2}{*}{$x^{2}$} & \multirow[b]{2}{*}{$\boldsymbol{P}$} \\
\hline & No. & $\%$ & No. & $\%$ & & \\
\hline $\begin{array}{l}\text { Used literature } \\
\square \text { From hospital/ } \\
\text { residency } \\
\square \text { From school }\end{array}$ & $\begin{array}{l}31 \\
10\end{array}$ & $\begin{array}{r}24.4 \\
7.9\end{array}$ & $\begin{array}{r}25 \\
4\end{array}$ & $\begin{array}{r}48.1 \\
7.7\end{array}$ & $\begin{array}{l}9.61 \\
0.00\end{array}$ & $\begin{array}{r}<.002 \\
\mathrm{NS}^{\dagger}\end{array}$ \\
\hline $\begin{array}{l}\text { Talked with } \\
\square \text { Experienced DO } \\
\square \text { Experienced MD } \\
\square \text { DO residents } \\
\square \text { MD residents } \\
\square \text { DO interns } \\
\square \text { MD interns }\end{array}$ & $\begin{array}{r}29 \\
5 \\
76 \\
13 \\
58 \\
12\end{array}$ & $\begin{array}{r}22.8 \\
3.9 \\
59.8 \\
10.2 \\
45.7 \\
9.4\end{array}$ & $\begin{array}{r}14 \\
8 \\
22 \\
22 \\
15 \\
13\end{array}$ & $\begin{array}{l}26.9 \\
15.4 \\
42.3 \\
42.3 \\
28.8 \\
25.0\end{array}$ & $\begin{array}{r}0.33 \\
7.18 \\
4.58 \\
24.13 \\
4.32 \\
7.43\end{array}$ & $\begin{aligned} & \text { NS } \\
&<<.008 \\
&<.04 \\
&<<.01 \\
&<.04 \\
&<.007\end{aligned}$ \\
\hline Personal experience & 3 & 2.4 & 2 & 3.8 & 0.30 & NS \\
\hline $\begin{array}{l}\text { *OIs }=\text { osteopathic ideologist } \\
\text { +NS }=\text { not statistically signi } \\
\text { NOTE: Because respondent } \\
\text { responses exceeds the numbe }\end{array}$ & $\begin{array}{l}\text { Als = } \\
\text { nt. } \\
\text { ere ir }\end{array}$ & hic ide & na & ress & tot: & $\begin{array}{l}\text { iber of the } \\
00 \text {. }\end{array}$ \\
\hline
\end{tabular}

reported having first applied to an osteopathic medical college (Table 2). However, OIs were less likely than AIs to have applied initially to an allopathic medical school $(37.8 \%$ vs $98.1 \%$, respectively). No significant differences were found between OIs' and AIs' acceptance rates to an allopathic program after having first applied to an osteopathic medical school ( $16.4 \%$ vs $9.1 \%$, respectively).

When asked to choose between two hypothetical residencies at hospitals identical in all respects except for their ideological orientations, OIs were more than twice as likely as AIs to choose an osteopathic residency $(84.0 \%$ vs $40.0 \%$, respectively).

\section{Adherence to osteopathic tenets}

Not surprisingly, the OI and AI interns answered differently on all five of the questions in this category. For example, OIs were more likely than AIs to agree that specialization keeps the physician from understanding the "whole" person $(37.0 \%$ vs $18.4 \%$, respectively; $\left.\chi^{2}=5.56 ; P<.02\right)$. This group also believed that a primary advantage of osteopathic medicine is its more holistic orientation $(86.1 \%$ vs $63.6 \%$, respectively; $\left.\chi^{2}=9.98 ; P<.002\right)$.
By contrast, AIs were more likely than OIs to agree that general practitioners know too little about specific medical conditions to make the best treatment decisions $(60.4 \%$ vs $28.7 \%$, respectively; $\left.\chi^{2}=14.46 ; P<<.01\right)$. Likewise, AIs also thought that OMT is of limited practical utility. As such, other treatments are being used in place of OMT $(40.0 \%$ vs $17.8 \%$, respectively; $\left.\chi^{2}=8.82 ; P<.003\right)$.

More AIs than OIs agreed that for all practical purposes, osteopathic and allopathic medical philosophies are the same $(68.6 \%$ vs $39.8 \%$, respectively; $\left.\chi^{2}=11.82 ; P<<.01\right)$.

\section{Evaluation of education quality}

As in the previous category, interns in both groups answered questions here differently. A higher proportion of OIs judged an osteopathic medical education superior to an allopathic medical education (Table 3 ). Conversely, AIs were more likely than OIs to consider an osteopathic medical education and residency inferior to an allopathic medical education and residency (Table 3 ). This group was also more likely than OIs to report feeling inferior to allopathic students or physicians at comparable stages of training $(P<.02$; Table 4$)$. 
Although AIs viewed osteopathic education and training as inferior to an allopathic track, both AIs and OIs evaluated osteopathic and allopathic hospitals nearly the same (Table 5).

\section{Plans for future training}

In this category, interns were asked about the nature of their future residencies, how they evaluated their residencies, and what factors influenced their final decision. Significant differences were noted between both groups on three out of four questions. Furthermore, within each ideologic group, interns named significantly varied factors that influenced their choice of residencies.

Concerning the nature of their residencies, AIs were more likely than OIs to choose a specialty residency other than family medicine $\left(74.0 \%\right.$ vs $54.5 \%$, respectively; $\chi^{2}=5.67$; $P<.02$ ). Meanwhile, OIs chose equally between family medicine residencies and other specialty residencies $(45.5 \%$ and $54.5 \%$, respectively).

In addition, the AIs were significantly more likely to choose a university-affiliated internship than OIs $(81.6 \%$ vs $32.5 \%$, respectively; $\left.\chi^{2}=34 ; P<<.01\right)$. Interns in both groups expressed similar opinions regarding the benefits of a community-based residency-one in which residents rotate through several hospitals in the same community $(53.4 \%$ vs $54.3 \%$, respectively; $\chi^{2}=.01$ ).

Similarly, both groups reported that their discussions with other residents, more than almost any other factor, influenced how they evaluated their chosen residency. Predictably, OIs sought advice more often from osteopathic residents $(P<.04)$, whereas AIs were more likely to speak with allopathic residents $(P<<.01$; Table 5).

This affinity was established early in the surveyed interns' training when they were likely to seek advice from philosophically aligned interns: OIs spoke to osteopathic interns more often $(P<.04)$ than did AIs who sought advice from allopathic interns $(P<.007$; Table 5).

Furthermore, AIs reported talking with an experienced MD $(P<.008)$ and to have been influenced by hospital literature and the resi- dency program more so than OIs (Table 6). Even after seeking advice from philosophically aligned interns and residents, the surveyed interns in both groups indicated that the quality of training and the location of their chosen residency most influenced their decision in this area (Table 6).

\section{Future career plans}

This category tapped the respondents' attitudes regarding their careers in six specific areas: the impact of the type of medical degree earned and chosen residency; where they would like to live; the type of hospital in which they would like to obtain practice privileges; and their plans for incorporating osteopathic philosophies and OMT in their future practice. Significant differences between both groups were found on all six questions.

Specifically, OIs were more likely than AIs to believe that an osteopathic residency would enhance their careers $(P<<.01)$. Conversely, AIs were significantly more likely than were OIs to believe that an allopathic residency would enhance their careers $(P<<.01$; Table 7).

However, the majority of respondents in both groups thought that the DO degree has a mixed effect on their practice. Respondents with definitive feelings in this area split along philosophic lines as might be expected (Table 7).

Approximately $50 \%$ of the respondents in each group wanted practice privileges in both osteopathic and allopathic hospitals. No differences existed in the proportion of interns in each group who wanted practice privileges at a mixed-staff hospital or expressed no preference. However, AIs were more likely than OIs to desire privileges in an allopathic hospital alone $(P<.04)$. Osteopathic ideologists were more likely than AIs to desire privileges at an osteopathic hospital only $(P<.02$; Table 8$)$.

More AIs than OIs (54.9\% vs $37.0 \%$, respectively) who knew where they planned to live and practice, following their training, were likely to do so within 50 miles of their training site (Table 8).

Finally, OIs were more likely than AIs to indicate that they plan on using osteopathic 


\begin{tabular}{|c|c|c|c|c|}
\hline \multicolumn{5}{|c|}{$\begin{array}{c}\text { Table } 6 \\
\text { Factors Influencing Choice of Residency* }\end{array}$} \\
\hline \multirow[b]{2}{*}{ Factor } & \multicolumn{2}{|c|}{$\begin{array}{c}\text { OIs } \dagger \\
(n=127)\end{array}$} & \multicolumn{2}{|c|}{$\begin{array}{c}\text { AIs } \\
(\mathbf{n}=\mathbf{5 2})\end{array}$} \\
\hline & No. & $\%$ & No. & $\%$ \\
\hline$\square$ Quality of training & 58 & 45.7 & 30 & 57.7 \\
\hline$\square$ Quality of faculty & 21 & 16.5 & 4 & 7.7 \\
\hline$\square$ Salary & 2 & 1.6 & 1 & 1.9 \\
\hline$\square$ Convenient location & 32 & 25.2 & 14 & 26.9 \\
\hline$\square$ Prestige of institution & 2 & 1.6 & 3 & 5.8 \\
\hline Better future opportunity for practice & 18 & 14.2 & 4 & 7.7 \\
\hline$\square$ Best exposure to osteopathic philosophy & 7 & 5.5 & $\mathrm{NA} \ddagger$ & \\
\hline$\square$ Best exposure to practice of OMT $\$$ & 3 & 2.4 & NA & \\
\hline \multirow{2}{*}{$\begin{array}{l}\square \text { Increased volume and diversity of } \\
\text { patient load } \\
\square \text { All osteopathic and AOA-approved } \\
\text { slots were filled }\end{array}$} & NA & & 4 & 7.7 \\
\hline & NA & & 1 & 1.9 \\
\hline \multicolumn{5}{|c|}{$\begin{array}{l}\text { *Respondents answered different questions depending on whether their residencies were AOA-approved. Thus, } \\
\text { some responses were not available to respondents in both groups. } \\
\text { FOIs = osteopathic ideologists; AIs = allopathic ideologists. } \\
\text { tNA }=\text { not asked. } \\
\text { SOMT }=\text { osteopathic manipulative treatment. } \\
\text { NOTE: Because respondents were instructed to select all applicable responses, the total number of the } \\
\text { responses exceeds the number in the sample population }(\mathrm{n}) \text { and the sum of the percentages is not } 100 \text {. }\end{array}$} \\
\hline
\end{tabular}

\begin{tabular}{|c|c|c|c|c|c|c|}
\hline \multicolumn{7}{|c|}{$\begin{array}{c}\text { Table 7 } \\
\text { Effect of Type of Residency and } \\
\text { 'Doctor of Osteopathy' (DO) Degree on Career }\end{array}$} \\
\hline \multirow[b]{2}{*}{ Variable } & \multicolumn{2}{|c|}{ OIs* } & \multicolumn{2}{|c|}{ AIs } & \multirow[b]{2}{*}{$x^{2}$} & \multirow[b]{2}{*}{$P$} \\
\hline & No. & $\%$ & No. & $\%$ & & \\
\hline $\begin{array}{l}\text { Type of residency } \\
\text { most likely to } \\
\text { enhance career } \\
\square \text { Osteopathic } \\
\square \text { Allopathic } \\
\square \text { No effect }\end{array}$ & $\begin{array}{l}(\mathbf{n} \\
60 \\
20 \\
46\end{array}$ & $\begin{array}{r}\text { 126) } \\
47.6 \\
15.9 \\
36.5\end{array}$ & $\begin{array}{r}1 \\
44 \\
5\end{array}$ & $\begin{array}{r}\text { 50) } \\
2.0 \\
88.0 \\
10.0\end{array}$ & $\begin{array}{l}32.89 \\
80.47 \\
12.22\end{array}$ & $\begin{array}{l}<<.01 \\
<<.01 \\
<<.01\end{array}$ \\
\hline $\begin{array}{l}\text { Overall effect of } \\
\text { DO degree } \\
\square \text { Helps } \\
\square \text { Mixed } \\
\square \text { Hurts }\end{array}$ & $\begin{array}{r}(\mathbf{n} \\
23 \\
92 \\
8\end{array}$ & $\begin{array}{r}123) \\
18.7 \\
74.8 \\
6.5\end{array}$ & $1^{1}+1$ & $\begin{array}{r}\text { 52) } \\
1.9 \\
78.8 \\
19.2\end{array}$ & $\begin{array}{l}8.69 \\
0.32 \\
6.42\end{array}$ & $\begin{array}{l}<.004 \\
\text { NS } \\
<.02\end{array}$ \\
\hline $\begin{array}{l}\text { *OIs }=\text { osteopathic ideolo } \\
\text { †NS }=\text { not statistically sig } \\
\text { NOTE: In some instances } \\
\text { the population }(\mathrm{n}) \text { may val }\end{array}$ & $\begin{array}{l}\text { Is }=a \\
\text { t. } \\
\text { ery int }\end{array}$ & $\begin{array}{l}\text { thic id } \\
\text { answer }\end{array}$ & quest & 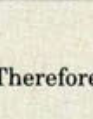 & mber in & sample of \\
\hline
\end{tabular}

principles in the treatment of most or all of their patients in the future $(67.5 \%$ vs $39.2 \%$, respectively; $\chi^{2}=11.92 ; P<<.01$ ). Conversely, AIs were more likely than OIs to indicate that they would practice osteopathic principles in the treatment of less than $50 \%$ of their patients or not at all (Table 8 ). Not surprisingly, $81.7 \%$ of OIs indicated that they would use OMT in their future practice compared with only $46.9 \%$ of AIs. More AIs (36.7\%) than OIs (16.7\%) ex- 
Table 8

Desires and Considerations Related to Future Practice

\begin{tabular}{|c|c|c|c|c|c|c|}
\hline \multirow[b]{2}{*}{ Variable } & \multicolumn{2}{|c|}{ OIs* } & \multicolumn{2}{|c|}{ AIs } & \multirow[b]{2}{*}{$x^{2}$} & \multirow[b]{2}{*}{$P$} \\
\hline & No. & $\%$ & No. & $\%$ & & \\
\hline Desired setting & \multicolumn{2}{|c|}{$(n=126)$} & \multicolumn{2}{|c|}{$(n=51)$} & & \\
\hline$\square$ Allopathic hospital only & 1 & 0.8 & 3 & 5.9 & 4.26 & $<.04$ \\
\hline$\square$ Osteopathic hospital only & 13 & 10.3 & 0 & 0.0 & 5.68 & $<.02$ \\
\hline Osteopathic and & & & & & & \\
\hline allopathic hospitals & 63 & 50.0 & 27 & 52.9 & 0.13 & $\mathrm{NS}^{\dagger}$ \\
\hline$\square$ Mixed-staff hospital & 33 & 26.2 & 9 & 17.6 & 1.46 & NS \\
\hline$\square$ No preference & 16 & 12.7 & 12 & 23.5 & 3.20 & NS \\
\hline $\begin{array}{l}\text { Planned location of } \\
\text { residence and practice } \\
\text { within } 50 \text { miles of } \\
\text { training site }\end{array}$ & \multicolumn{2}{|c|}{$(\mathrm{n}=127)$} & \multicolumn{2}{|c|}{$(\mathrm{n}=51)$} & & \multirow{4}{*}{$\begin{array}{r}<.03 \\
\text { NS } \\
<.03\end{array}$} \\
\hline$\square$ Yes & 47 & 37.0 & 28 & 54.9 & 4.78 & \\
\hline Not sure & 48 & 37.8 & 18 & 35.3 & 0.10 & \\
\hline$\square$ No & 32 & 25.2 & 5 & 9.8 & 5.24 & \\
\hline Plan to use OMT & \multicolumn{2}{|c|}{$(n=126)$} & \multicolumn{2}{|c|}{$(n=49)$} & & \\
\hline$\square$ Yes & 103 & 81.7 & 23 & 46.9 & & $<<.01$ \\
\hline Maybe/unsure & 21 & 16.7 & 18 & 36.7 & 8.20 & $<.005$ \\
\hline$\square$ No & 2 & 1.6 & 8 & 16.3 & 14.23 & $<<.01$ \\
\hline
\end{tabular}

pressed uncertainty concerning the use of osteopathic principles in their future practice.

\section{Coherence and integration of training}

In this category, respondents reported how often osteopathic philosophy and OMT were mentioned in the classroom and in the clinic. Interns also indicated how many professors helped them integrate osteopathic philosophy and OMT into their clinical practice. No significant differences were found between the groups on any of the eight questions in this category (Table 9). Such consistency is extraordinary given the remarkably strong differences between both groups found in every other category.

Further data inspection revealed a fairly consistent response pattern: Most respondents in both groups reported little exposure to either osteopathic philosophy or OMT. Likewise, interns reported that professors made only a small effort to help the interns integrate either osteopathic philosophy or OMT into their clinical practice.

We tested this pattern by combining the two ideologic groups and subjecting their responses to one-sample $\chi^{2}$ tests for equal proportions, using SPSS-X. These analyses confirmed our initial observations. Namely, the interns as a group indicated that during their classroom and clinical years few of their professors exposed them to osteopathic philosophy. In addition, a significant proportion of the interns characterized the frequency of their exposure, at least during the clinical years, as being either once in a while or never. Furthermore, interns reported that few of their professors taught them how to integrate OMT principles into their practice $(P<<.01$ for each indicator; Table 10 ). The only reported exception to this pattern was that interns were mixed when characterizing the frequency of their exposure to osteopathic philosophy during their classroom years (Table 10). 
Most respondents in both groups report being taught how to perform OMT in the classroom. At the time they filled out the questionnaire, most respondents reported being able to perform OMT (Table 11).

\section{Discussion}

The results reported in this current study reveal striking differences among the attitudes of two distinct groups of interns training at AOA-approved training sites across the United States. Differentiation between survey respondents was based on the students' first choice of medical school and residency program. The interns' responses differed significantly concerning their preparation for and commitment to an osteopathic medical career; adherence to osteopathic tenets; plans for future training; and career plans.
In other words, the differences between the students in the two groups apparently existed before respondents applied to an osteopathic medical school. These differences persisted throughout medical training, influencing each intern's plans for the future.

Substantial evidence suggests that most, if not all, of the respondents classified as AIs qualify as backdoor students. They chose osteopathic medicine as an alternative route into a medical career, rather than as an alternative form of medical practice. By definition, the AIs would have preferred to attend an allopathic medical school and residency. However, $90 \%$ of AIs failed to be accepted into an allopathic program when they first applied to medical school; $75 \%$ of them cited this failure as reason for choosing to enter a school of osteopathic medicine.

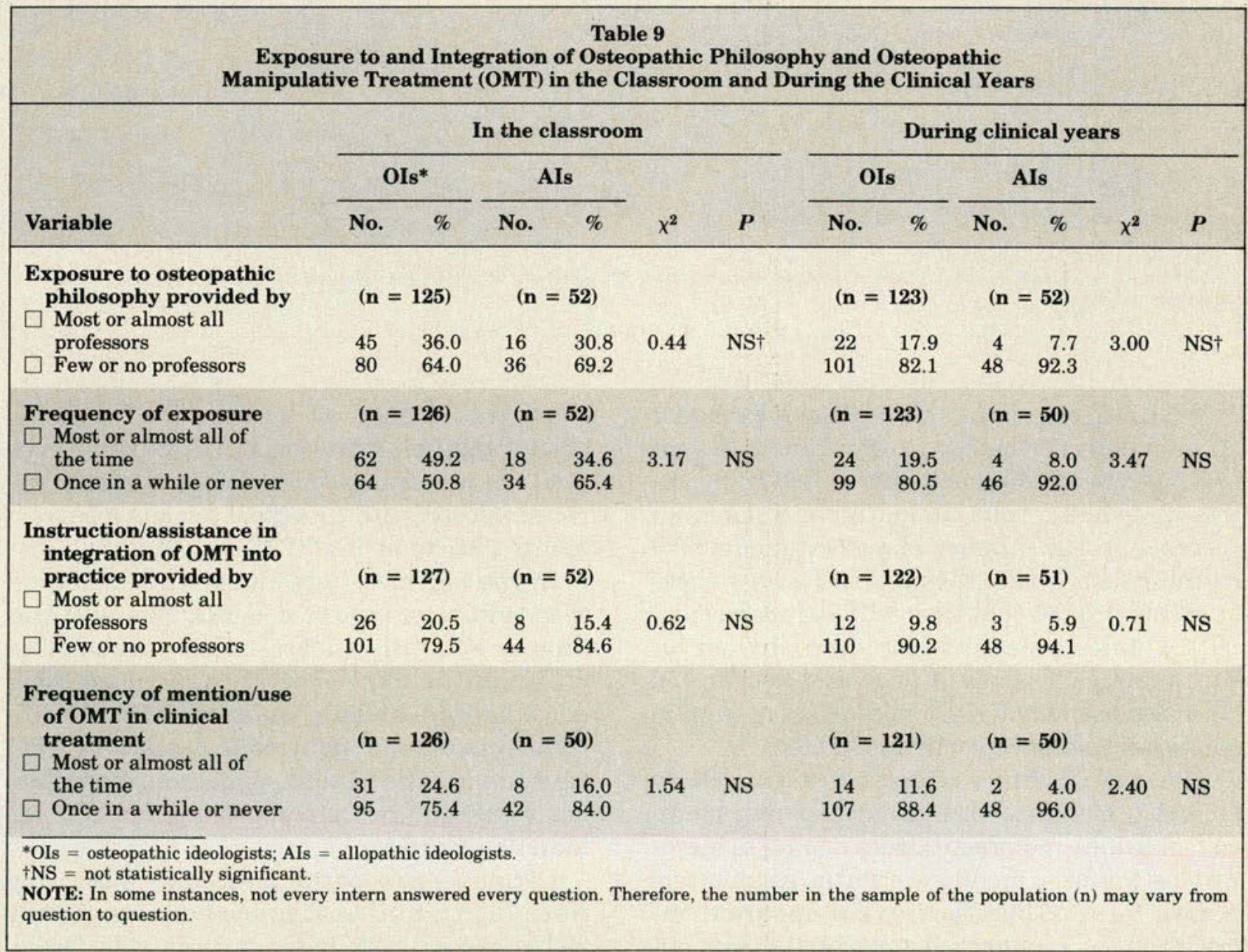


Table 10

Exposure to and Integration of Osteopathic Philosophy and Osteopathic Manipulative Treatment (OMT) in the Classroom and During the Clinical Years-All Interns

\begin{tabular}{|c|c|c|c|c|c|c|c|c|}
\hline \multirow[b]{2}{*}{ Variable } & \multicolumn{4}{|c|}{ In the classroom } & \multicolumn{4}{|c|}{ During clinical years } \\
\hline & No. & $\%$ & $\chi^{2}$ & $\boldsymbol{P}$ & No. & $\%$ & $x^{2}$ & $P$ \\
\hline \multirow{2}{*}{$\begin{array}{l}\text { Exposure to osteopathic } \\
\text { philosophy provided by } \\
\square \text { Most or almost all } \\
\text { professors } \\
\square \text { Few or no professors }\end{array}$} & \multirow{2}{*}{\multicolumn{4}{|c|}{$(n=177)$}} & \multicolumn{4}{|c|}{$(n=175)$} \\
\hline & & & & & $\begin{array}{r}26 \\
149\end{array}$ & $\begin{array}{l}14.9 \\
85.1\end{array}$ & 86.45 & $<<.01$ \\
\hline \multirow{3}{*}{$\begin{array}{l}\text { Frequency of exposure } \\
\square \text { Most or almost all of } \\
\text { the time } \\
\square \text { Once in a while or } \\
\text { never }\end{array}$} & \multicolumn{3}{|c|}{$(n=178)$} & \multirow{3}{*}{ NS* } & \multicolumn{3}{|c|}{$(n=173)$} & \\
\hline & 80 & 44.9 & 1.82 & & 28 & 16.2 & 79.13 & $<<.01$ \\
\hline & 98 & 55.1 & & & 145 & 83.8 & & \\
\hline \multirow{2}{*}{$\begin{array}{l}\text { Instruction/assistance } \\
\text { in integration of OMT } \\
\text { into practice } \\
\text { provided by } \\
\square \text { Most or almost all } \\
\text { professors } \\
\square \text { Few or no professors }\end{array}$} & \multicolumn{3}{|c|}{$(n=179)$} & & \multicolumn{3}{|c|}{$(n=173)$} & \\
\hline & $\begin{array}{r}34 \\
145\end{array}$ & $\begin{array}{l}19.0 \\
81.0\end{array}$ & 68.83 & $<<.01$ & $\begin{array}{r}15 \\
158\end{array}$ & $\begin{array}{r}8.7 \\
91.3\end{array}$ & 118.20 & $<<.01$ \\
\hline \multirow{3}{*}{$\begin{array}{l}\text { Frequency of mention/use } \\
\text { of OMT in clinical } \\
\text { treatment } \\
\square \text { Most or almost all of } \\
\text { the time } \\
\square \text { Once in a while or never }\end{array}$} & \multicolumn{3}{|c|}{$(n=176)$} & & \multicolumn{3}{|c|}{$(n=171)$} & \\
\hline & 39 & 22.2 & 54.57 & $<<.01$ & 16 & 9.4 & 112.99 & $<<.01$ \\
\hline & 137 & 77.8 & & & 155 & 90.6 & & \\
\hline
\end{tabular}

What effects might this influx of backdoor students have on osteopathic medicine in general? If osteopathic medicine is becoming indistinguishable from allopathic medicine, an increase in the number of such students will certainly exacerbate the process, because these students predict that they will abandon osteopathic philosophies and procedures in their future practice. Clearly, AIs cannot be counted on to act as champions, advocates, or even mild supporters of osteopathic medicine.

The AIs' attitudes expressed in this study should prove unsettling to osteopathic medical educators and practitioners hoping to maintain osteopathic medicine's status as an alternative form of healthcare. An apparent increase in the number of backdoor students en- rolled in colleges of osteopathic medicine should magnify this concern. (As noted earlier, the percentage of backdoor students enrolled in osteopathic medical schools rose from $5 \%$ in 1967 to at least $28 \%$ in $1987 .^{4-6}$ )

In the current study, about $10 \%$ of the respondents were classified as AIs. However, this number seriously underestimates the number of AIs in the total population, because those AIs who were able to obtain an allopathic internship were not included in our survey. Had we examined the total AI population, their number would likely have approximated $28 \%$, as found by Eckberg. ${ }^{6}$

Of course, osteopathic medicine's increasing resemblance to allopathic medicine can hardly be blamed entirely on the influx of AIs. Osteo- 


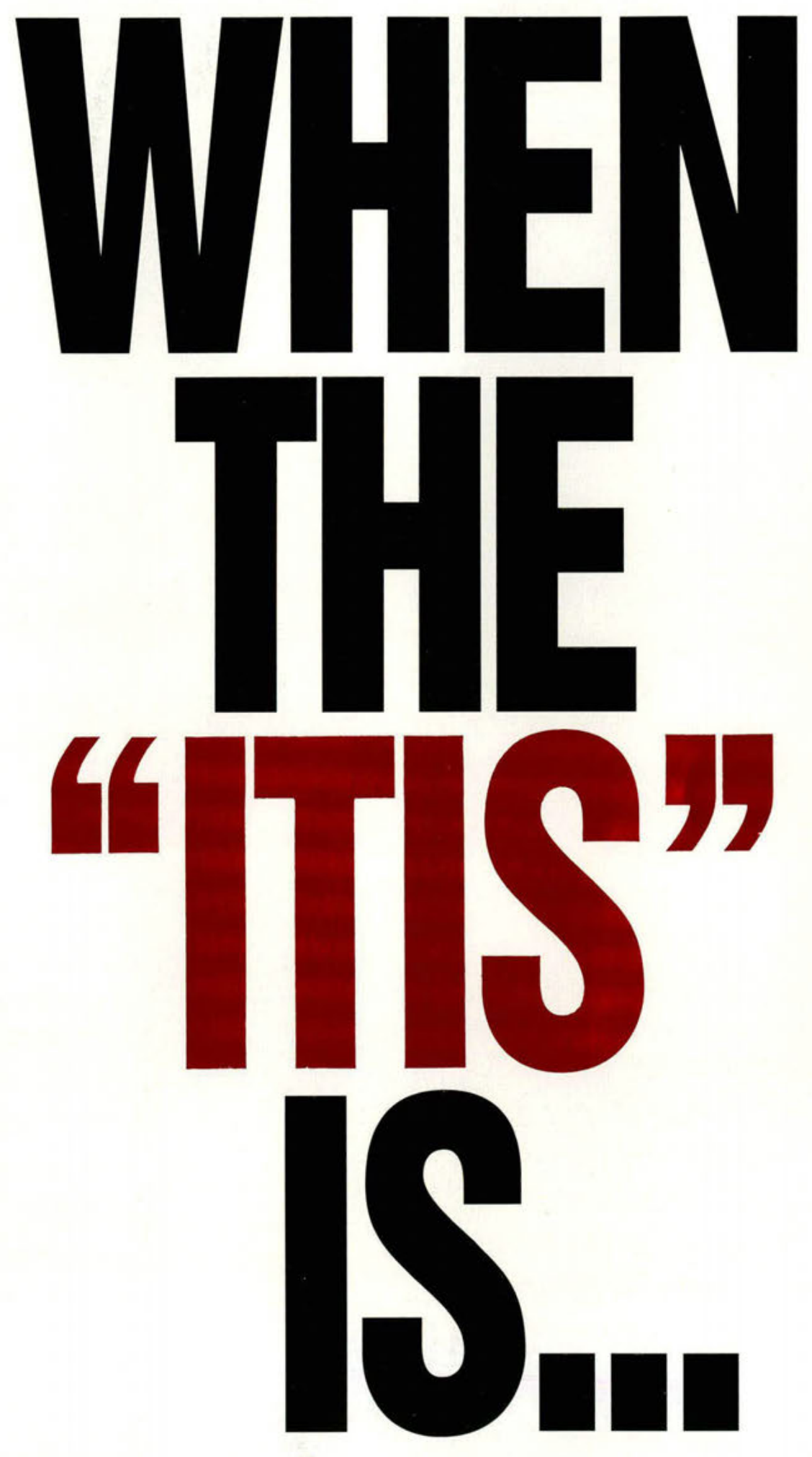




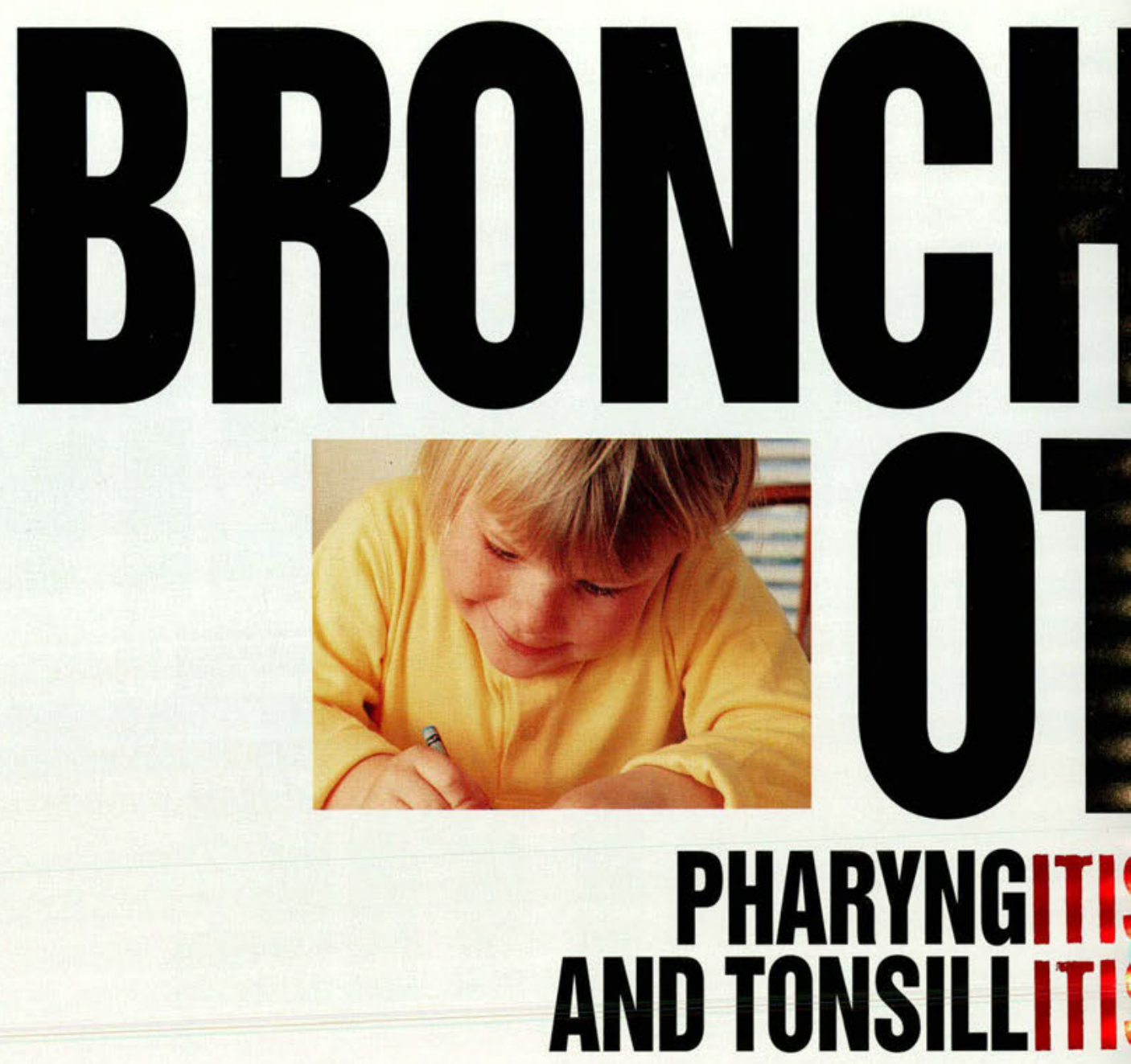

- SUPRAX: the most potent oral cephalosporin in vitro ${ }^{\dagger}$ against B-lactamase+ pathogens ${ }^{1}$

- SUPRAX: produces bronchial concentrations at least 6 times higher than the $\mathrm{MIC}_{90}$ of common respiratory pathogens ${ }^{2}$

- SUPRAX: attains outstanding clinical efficacy - cured/improv $96 \%$ of otitis media cases ${ }^{3}$ and $95.8 \%$ of bronchitis cases ${ }^{4}$

- SUPRAX: an alternative to traditional therapy in cases of pharyngitis/tonsillitis. Once-daily dosage enhances complianc

- SUPRAX: best tasting oral antibiotic suspension ${ }^{5}$ 


\section{ONCE-A-DAY} SUPRAX

\section{SUPRAX HAS BEEN USED SAFELY IN OVER 17 MLLION PATIENTS WORLDWDE ${ }^{6}$}

References: 1. Nash DR, Flanagan C. Steele LC, Wallace RJ Jr. A comparison of the activity of cefixime with other oral antibiotics against adult clinical isolates of Moraxella (Branhame/la) Catarmhalis containing BRO-1 and BRO-2 and Haemophilus influenzae. Antimicrob Agents Chemother. 1991;35:192-194. 2. Baldwin DR, Andrews JM. A shby JP, et al. Concentrations of cefixime in bronchial mucosa and sputum after three oral multiple dose regimens. Thorax 1990; $45 ; 401-402$. 3. McLinn SE. A clinician's perspective of acute otitis multiple dose regimens. Thorax 1990; $45.401-402.3$ McLia in Lederle Laboratories, Pearl River, NY. 4. Verghese A, Roberson D, Kalbfleisch JH, et al. Randomized Antimicrob Agents Chemother. 1990;34:1041-1044. 5. Ruft ME, Schotik DA, Bass JW, Vincent JM. Antimicrobial drug suspensions: a blind comparison of taste of fourteen common pediatric drugs. Pediat Antimicrobial drug suspensions: a blind comparison of taste of fourteen common per.
Infect Dis J. 1991:10:30-33. 6. Data on file, Lederle Laboratories, Pearl River, NY.

\section{SUPRAX ${ }^{*}$ cefixime/Lederle}

BRIEF SUMMARY. Please see package insert for full Prescribing Information INDICATIONS AND USAGE

Otitis Media caused by Haemophilus influenzae (beta-lactamase positive and negative strains), Moraxella (Branhamella) catarrhalis (most of which are beta-lactamase positive) and Streptococcus pyogenes

Note: For information on otitis media caused by Streptococcus pneumoniae, see CLINICAL STUDIES section

Acute Bronchitis and Acute Exacerbations of Chronic Bronchitis caused by S pneumoniae and Hinfluenzae (beta-lactamase positive and negative strains)

Perform culture and susceptibility studies to determine causative organism and its susceptibility to SUPRAX. Therapy may begin while waiting for study results and may be adjusted when results are known.

Pharyngitis and Tonsillitis caused by $S$ pyogenes.

Note: Penicillin is the usual drug of choice in the treaiment of $S$ pyogenes infections, includ ing the prophylaxis of rheumatic fever. SUPRAX is generally effective in the eradication of Spyogenes from the nasopharynx; however, data establishing the efficacy of SUPRAX in the subsequent prevention of rheumatic fever are not available.

列 Efficacy for this organism was studied in fewer than ten patients with otitis media.

CLINICAL STUDIES

In clinical trials of otitis media in nearly 400 children between the ages of 6 months and 10 years, $S$ pneumoniae was isolated from $47 \%$ of the patients. $H$ influenzae from $34 \%$, $B$ catarrhalis from $15 \%$, and S pyogenes from $4 \%$.

The overall response rate of $S$ pneumoniae to cefixime was approximately $10 \%$ lower and that of $H$ influenzae or $B$ catarrhalis approximately $7 \%$ higher $(12 \%$ when beta-lactamase positive strains of $H$ influenzae are included) than the response rates of these organisms to the active control drugs.

In these studies, patients were randomized and treated with either cefixime at dose regimens of $4 \mathrm{mg} / \mathrm{kg}$ bid or $8 \mathrm{mg} / \mathrm{kg}$ qd, or with a standard antibiotic regimen. Sixty-nine to $70 \%$ of the patients in each group had resolution of signs and symptoms of otitis media when evaluated two to four weeks posttreatment, but persistent effusion was found in $15 \%$ of the patients. When evaluated at the completion of therapy, $17 \%$ of patients receiving cefixime and $14 \%$ of patients receiving effective comparative drugs ( $18 \%$ including those patients who had $H$ influenzae resistant to the control drug and who received the control antibiotic) were considered to be treatment failures. By the two- to four-week follow-up, a total of $30 \%$ to $31 \%$ of patients had evidence of either treatment failure or recurrent disease.

\begin{tabular}{|c|c|c|c|}
\hline \multicolumn{4}{|c|}{$\begin{array}{l}\text { Bacteriological Outcome of Otitis Media at Two- to Four-Weeks Posttherapy } \\
\text { Based on Repeat Middle Ear Fluid Culture or Extrapolation from Clinical Outcome }\end{array}$} \\
\hline Organism & $\begin{array}{l}\text { Cefixime(a) } \\
4 \mathrm{mg} / \mathrm{kg} \text { bid }\end{array}$ & $\begin{array}{l}\text { Cefixime(a) } \\
8 \mathrm{mg} / \mathrm{kg} \text { qd }\end{array}$ & $\begin{array}{l}\text { Control(a) } \\
\text { drugs }\end{array}$ \\
\hline $\begin{array}{l}\text { Streptococcus pneumoniae } \\
\text { Haemophilus influenzae }\end{array}$ & $48 / 70 \quad(69 \%)$ & $18 / 22(82 \%)$ & $82 / 100(82 \%)$ \\
\hline $\begin{array}{l}\text { beta-lactamase negative } \\
\text { Haemophilus influenzae }\end{array}$ & $24 / 34(71 \%)$ & $13 / 17(76 \%)$ & $23 / 34(68 \%)$ \\
\hline $\begin{array}{l}\text { beta-lactamase positive } \\
\text { Moraxella (Branhamella) }\end{array}$ & $17 / 22(77 \%)$ & $9 / 12(75 \%)$ & $1 / 1$ (b) \\
\hline $\begin{array}{l}\text { catarrhalis } \\
\text { Streptococcus pyogenes }\end{array}$ & $\begin{array}{c}26 / 31 \\
5 / 5\end{array}$ & $\begin{array}{l}5 / 5 \\
3 / 3\end{array}$ & $\begin{array}{c}18 / 24(75 \%) \\
6 / 7\end{array}$ \\
\hline All Isolates & $120 / 162(74 \%)$ & $48 / 59(81 \%)$ & $130 / 166(78 \%)$ \\
\hline
\end{tabular}

\section{a) Number eradicated/number isolated}

b) An additional 20 beta-lactamase positive strains of $H$ influenzae were isolated, but were excluded from this analysis because they were resistant to the control antibiotic. In 190 these the clinical course could be assessed, and a favorable outcome occurred in 10 . When these cases are included in the overall bacteriological evaluation of therapy with the control drugs, $140 / 185(76 \%)$ of pathogens were considered to be eradicated.

Tablets should not be substituted for suspension when treating otitis media

\section{CONTRAINDICATIONS}

to cephalosporins.

NARNING

BEFORE THERAPY WITH SUPRAX IS INSTITUTED, CAREFUL INQUIRY SHOULD BE MADE TO DETERMINE WHETHER THE PATIENT HAS HAD PREVIOUS HYPERSENSITIV ITY REACTIONS TO CEPHALOSPORINS, PENICILLINS, OR OTHER DRUGS. IF THIS PRODUCT IS TO BE GIVEN TO PENICILLIN-SENSITIVE PATIENTS, CAUTION SHOULD BE EXERCISED BECAUSE CROSS-HYPERSENSITIVITY AMONG BETA-LACTAM ANTIBIOTICS HAS BEEN CLEARLY DOCUMENTED AND MAY OCCUR IN UP TO $10 \%$ OF PATIENTS WITH A HISTORY OF PENICILLIN ALLERGY. IF AN ALLERGIC REACTION TO

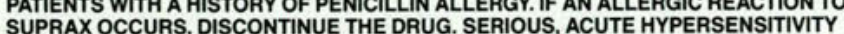
SUPRAX OCCURS, DISCONTINUE THE DRUG. SERIOUS, ACUTE HYPERSENSITIVITY REACTIONS MAY REQUIRE TREATMENT WITH EPINEPHRINE AND OTHER EMERGENCY MEASURES, INCLUDING OXYGEN, INTRAVENOUS FLUIDS, INTRAVENOUS
ANTIHISTAMINES, CORTICOSTEROIDS, PRESSOR AMINES, AND AIRWAY MANAGEMENT, AS CLINICALLY INDICATED.

Treatment with broad-spectrum antibiotics alters the normal flora of the colon and may permit overgrowth of clostridia. Studies indicate that a toxin produced by Clostridium difficile is a primary cause of severe antibiotic-associated diarrhea including pseudomembranous colitis Pseudomembranous colitis has been reported with the use of SUPRAX cefixime and other broad-spectrum antibiotics (including macrolides, semisynthetic penicillins, and cephalosporins). It is important to consider this diagnosis in patients who develop diarrhea in association with antibiotic use. Symptoms of pseudomembranous colitis may occur during or after antibiotic treatment and may range in severity from mild to life threatening. Mild cases usual respond to drug discontinuation alone. Moderate-to-severe cases should be managed with fluid, electrolyte, and protein supplementation. When the colitis is not relieved by drug discontinuance, or when it is severe, oral vancomycin is the drug of choice for antibioticassociated pseudomembranous colitis produced by $\mathrm{C}$ difficile. Other causes of colitis should be excluded

General: Prolonged use may result in overgrowth of nonsusceptible organisms. If superin-

ction occurs, take appropriate measures.

Carefully monitor patients on dialysis. Adjust dosage of SUPRAX in patients with renal impairment and those undergoing continuous ambulatory peritoneal dialysis and hemodialysis. (See DOSAGE AND ADMINISTRATION.

Prescribe cautiously in patients with a history of gastrointestinal disease, particularly colitis Drug Interactions: No significant drug interactions have been reported to date.

Drug/Laboratory Test Interactions: A false-positive reaction for ketones in the urine may ccur with tests using nitroprusside but not with those using nitroferricyanide.

SUPRAX administration may result in a false-positive reaction for glucose in the urine using Clinitest ${ }^{3}$ * Benedict's solution, or Fehling's solution. Use glucose tests based on enzymatic glucose oxidase reactions (such as Clinistix ${ }^{* * *}$ or Tes-Tape ${ }^{* *}$ ).

A false-positive direct Coombs test has been reported during treatment with other

cephalosporin antibiotics; therefore, it should be recognized that a positive Coombs test ma be due to the drug.

Carcinogenesis, Mutagenesis, Impairment of Fertility: Although no lifetime animal studie have been conducted to evaluate carcinogenic potential, no mutagenic potential of SUPRAX was found in standard laboratory tests. Reproductive studies revealed no fertility impairment in rats at doses up to 125 times the adult therapeutic dose.

Usage in Pregnancy: Pregnancy Category B: Reproduction studies have been performed mice and rats at doses up to 400 times the human dose and have revealed no evidence of harm to the fetus due to SUPRAX

There are no adequate and well-controlled studies in pregnant women. Because animal reproduction studies are not always predictive of human response, this drug should be used during pregnancy only if clearly needed

Labor and Delivery: SUPRAX has not been studied for use during labor and delivery. Treatment should only be given if clearly needed.

Nursing Mothers: It is not known whether SUPRAX is excreted in human milk. Consider discontinuing nursing temporarily during treatment with this drug

Pediatric Use: Safety and effectiveness of SUPRAX in children aged less than 6 months have not been established.

The incidence of gastrointestinal adverse reactions, including diarrhea and loose stools, in pediatric patients receiving the suspension, was comparable to adult patients receiving tablets.

\section{ADVERSE REACTIONS}

Most adverse reactions observed in clinical trials were of a mild and transient nature. Less than four percent (3.8\%) of patients in the US trials discontinued therapy because of drug related adverse reactions. Commonly seen adverse reactions in US trials of the tablet formulation were gastrointestinal events, which were reported in $30 \%$ of adult patients on either th bid or the qd regimen. Clinically mild gastrointestinal side effects occurred in $20 \%$ of all patients, moderate events occurred in $9 \%$ of all patients, and severe adverse reactions occurred in $2 \%$ of all patients. Individual event rates included diarrhea $16 \%$, loose or frequen , the incidenc of gastrointestinal adverse reactions, including diarrhea and loose stools, in pediatric patients receiving the suspension was comparable to adult patients receiving tablets. patients receiving the suspension was comparable to adult patients receiving tablets.
Symptoms usually responded to symptomatic therapy or ceased when SUPRAX was discontinued.

Several patients developed severe diarrhea and/or documented pseudomembranous colitis, and a few required hospitalization.

The following adverse reactions have been reported following the use of SUPRAX. Incidence rates were less than 1 in 50 (less than $2 \%$ ), except as noted above for gastrointestinal events.

Gastrointestinal: Diarrhea, loose stools, abdominal pain, dyspepsia, nausea, and vomiting Several cer studies The onset of pseudomembranous colitis symptoms may occur during or after therapy. Hypersensitivity Reactions: Skin rashes, urticaria, drug fever, and pruritus. Erythema mult forme. Stevens-Johnson syndrome, and serum sickness have been reported rarely. Hepatic: Transient elevations in SGPT, SGOT, and alkaline phosphatase.

Renal: Transient elevations in BUN or creatinine.

Central Nervous System: Headaches 3\%; dizziness.

Hemic and Lymphatic Systems: Transient thrombocytopenia, leukopenia, and eosinophilia Prolongation in prothrombin time was seen rarely.

Other: Genital pruritus, vaginitis, candidiasis.

The following adverse reactions and altered laboratory tests have been reported for cephalosporin-class antibiotics:

Adverse Reactions: Allergic reactions including anaphylaxis, toxic epidermal necrolysis, superinfection, renal dysfunction, toxic nephropathy, hepatic dysfunction, including cholest sis, aplastic anemia, hemolytic anemia, hemorrhage.

Several cephalosporins have been implicated in triggering seizures, particularly in patien with renal impairment when the dosage was not reduced (see DOSAGE AND ADMINISTRA TION and OVERDOSAGE). If seizures associated with drug therapy occur, discontinue dru Administer anticonvulsant therapy if clinically indicated.

Abnormal Laboratory Tests: Positive direct Coombs test, elevated bilirubin, elevated LDH pancytopenia, neutropenia, agranulocytosis.

OVERDOSAGE

Gastric lavage may be indicated; otherwise, no specific antidote exists. Cefixime is not

removed in significant quantities from the circulation by hemodialysis or peritoneal dialysis. Adverse reactions in small numbers of healthy adult volunteers receiving single doses up to 2 of SUPRAX did not differ from the profile seen in patients treated at the recommended dose " CClinitest and Clinistix are registered trademarks of Ames Division, Miles Laboratories, Inc. Tes-Tape is a registered trademark of Eli Lilly and Company.

LEDERLE LABORATORIES DIVISION

American Cyanamid Company. Pearl River, NY 10965

Rev. $6 / 9$

Under License of Fuijsawa Pharmaceutical Co., Ltd., Osaka, Japan

\section{Lederle Laboratories}

A Division of American Cyanamid Compan

Wayne, New Jersey 07470

Fil under uneneso of

ujisawa Pharmaceutical Co., Ltd.

C 1991 Lederle Laboratories 


\begin{tabular}{|c|c|c|c|c|c|c|}
\hline \multicolumn{7}{|c|}{$\begin{array}{l}\text { Table 11 } \\
\text { Status of Classroom Teaching and Ability to Perform } \\
\text { Osteopathic Manipulative Treatment (OMT) }\end{array}$} \\
\hline \multirow[b]{2}{*}{ Status } & \multicolumn{2}{|c|}{$\begin{array}{c}\text { OIs* } \\
(n=126)\end{array}$} & \multicolumn{2}{|c|}{$\begin{array}{c}\text { AIs } \\
(n=52)\end{array}$} & \multirow[b]{2}{*}{$x^{2}$} & \multirow[b]{2}{*}{$P$} \\
\hline & No. & $\%$ & No. & $\%$ & & \\
\hline $\begin{array}{l}\square \text { Taught and can } \\
\text { perform OMT }\end{array}$ & 116 & 92.1 & 45 & 86.5 & 1.30 & NSt \\
\hline $\begin{array}{l}\square \text { Taught but cannot } \\
\text { perform OMT }\end{array}$ & 9 & 7.1 & 5 & 9.6 & 0.31 & NS \\
\hline $\begin{array}{l}\square \text { Not taught to } \\
\text { perform OMT }\end{array}$ & 1 & 0.8 & 2 & 3.8 & 2.07 & NS \\
\hline $\begin{array}{l}\text { *OIs }=\text { osteopathic ideologis } \\
\text { +NS = not statistically sign } \\
\text { NOTE: In some instances, } n \\
\text { the population }(n) \text { may vary }\end{array}$ & $\begin{array}{l}\text { AIs }=2 \\
\text { cant. } \\
\text { every in } \\
\text { om quest }\end{array}$ & $\begin{array}{l}\text { athic ide } \\
\text { answer } \\
\text { o questi }\end{array}$ & ques & eref & b & aple o \\
\hline
\end{tabular}

pathic educators share some of this responsibility as the most striking findings of the current study are those regarding the respondents' perceptions of the coherence and integration of their training. Remarkably, on almost every item tapping this domain, an average of $82 \%$ of OIs and AIs reported little exposure to either osteopathic philosophy or OMT. Likewise, respondents noted little effort by their professors to help them integrate either osteopathic philosophy or OMT into clinical practice. Because of the substantial differences between both groups in every other surveyed area, the consistent agreement between the two groups in the area of coherence and integration of training should alarm those individuals who teach students to practice an alternative form of medicine. Osteopathic medicine can hardly hope to win converts among AIs - or consolidate support among OIs-if it does not clearly delineate and promote that which sets it apart from mainstream medicine.

Perhaps osteopathic medical schools need to increase their efforts to encourage and foster osteopathic ideals in the classroom-and clinic. Such an emphasis would provide students and interns with a clear picture of the unique contribution they are able to make by virtue of their training.

Several of the current study's findings suggest areas in need of additional investigation.
For example, at what point do prospective medical students develop their ideas regarding medical ideology and practice, and what factors influence this development? Are these ideas amenable to modification? Is it possible to transform an AI into an OI? If such a transformation is possible, is it desirable? To what extent does osteopathic medical education actually lack coherence and integration? What steps can be taken to address existing problems? What career paths do these two groups of ideologists tend to follow? What effects do these paths have on the field of osteopathic medicine?

The answers to these and other questions raised here should prove valuable to the continued growth and health of osteopathic medicine in general and to osteopathic medical education in particular.

\section{Conclusion}

Two of the aforementioned findings are particularly noteworthy. The first involves the marked differences between the osteopathic and allopathic ideologists: the two groups differed extensively on nearly every attitude examined. The second finding proves noteworthy, in part, because it strongly contradicts the first finding. Contrary to their disparate attitudes on nearly every other indicator, OIs and AIs completely agreed that their osteopathic 
education lacked coherence and an integration of osteopathic principles and practices.

Neither finding should please osteopathic medical educators and physicians wishing to maintain osteopathic medicine's status as an alternative form of healthcare. Osteopathic medicine will have difficulty remaining viable as an alternative to allopathic medicine if it does not actively promote that which makes it unique, and hence an alternative.

Of course, we are not suggesting that osteopathic physicians abandon all vestiges of allopathic philosophy and practice. On the contrary, osteopathic medicine should continue to embrace the best of what allopathic medicine has to offer. At the same time, osteopathic medicine must not only take care not to lose, but must vigorously champion, the best of what it has traditionally offered: a holistic, personcentered approach to the healing arts and sciences.

This study was made possible by the Michigan State University-College of Osteopathic Medicine. The authors would especially like to thank Dean Myron
Magen, DO, and Associate Dean Douglas Wood, $D O$, for their support; James Stapleton, $P h D$, and Chagadsh Gogatee, $P h D$, for their help with the preliminary statistical analyses: and Douglas Erkberg, $P h D$, for his permission to use questions from his previous study and for reviewing our project. The authors would also like to thank others who were instrumental in completing the study: John Williamson, MA; Karen Polanski, MA, and Javad Abu-Lughod, BS.

1. Michigan State University College of Osteopathic Medicine Admissions Catalog. Lansing, Mich, The Office of Health Information, 1987.

2. Special report: Board finalizes plans for internships, residencies. The DO 1989;30(5):78-79.

3. Gevitz N: Osteopathic Medicine: A social and political portrait. Dissertation proposal, University of Chicago, Department of Sociology, unpublished, 1975.

4. Mills LW: Osteopathic education. JAOA 1968;67:553-565.

5. O'Donnell AE: Motivation factors influencing a student's selection of osteopathic medicine as a career. JAOA 1971;70:485487.

6. Eckberg DL: The dilemma of osteopathic physicians and the rationalization of medical practice. Soc Sci Med 1987;25:11111120 .

7. Zobell DC: Annual Statistical Report. Rockville, Md, American Association of Colleges of Osteopathic Medicine, 1988. 


\title{
Incomplete rectal obstruction secondary to adenocarcinoma of the prostate
}

\author{
PRAGNESH A. DESAI, DO \\ ROBERT L. FIOERELLI, DO \\ LEONARD H. FINKELSTEIN, DO
}

\begin{abstract}
Ureteral and bladder outlet obstruction are well-known sequelae of adenocarcinoma of the prostate. Contiguous extension of prostate cancer locally to involve the rectum is an uncommon phenomenon. It has been suggested that this is because Denonvillier's fascia is an effective barrier to posterior extension of malignant prostatic neoplasms. Herein, we report a case of this unusual association as well as a review of the literature.

(Key words: Bowel obstruction, adenocarcinoma of the prostate, rectal mass)
\end{abstract}

In spite of the intimate anatomic relationship between the rectum and the prostate gland, prostatic carcinoma only infrequently involves the rectum. Estimates of the prevalence of this association range from $1.5 \%$ to $11.5 \% .{ }^{1}$ It has been suggested that Denonvillier's fascia is an effective barrier to posterior extension of malignant prostatic neoplasms and that this accounts for the infrequent phenomenon of rectal involvement. ${ }^{2,3}$ Only when

From the Division of Urology, Department of Surgery, Osteopathic Medical Center of Philadelphia, Philadelphia, $\mathrm{Pa}$, where, at the time this article was written, Dr Desai was chief resident and Dr Fiorelli, former chief resident; Dr Finkelstein is chairman. Currently, Dr Desai is attending urologist, Allentown $(\mathrm{Pa})$ Osteopathic Medical Center, and Dr Fiorelli is attending urologist, Geisinger Wyoming Medical Center, Wilkes-Barre, Pa.

Reprint requests to Pragnesh A. Desai, DO, $1422 \mathrm{Ha}-$ milton St, Allentown, PA 18102. this fascia is penetrated can posterior extension of the tumor occur.

A major problem presented by digital rectal examination is distinguishing between a primary colonic neoplasm and carcinoma of the prostate involving the rectum. The following case report and discussion illustrate this problem and indicate diagnostic modalities for differentiating between the malignancies.

\section{Report of case}

A 67-year old man was seen because he had diminution of his urinary stream, nocturia, and urinary hesitancy. Digital rectal examination revealed a hard, firm prostate gland. The serum prostatespecific antigen (PSA) level (Yang assay, Dianon Systems Inc, Stratford, Conn) was elevated at 772 $\mathrm{ng} / \mathrm{mL}$ (normal, 0 to $2.5 \mathrm{ng} / \mathrm{mL}$ ). Because of the abnormal findings, transrectal prostatic ultrasonography and a prostatic biopsy were performed. The ultrasonogram demonstrated a diffusely hypoechoic prostate, and the biopsy revealed a Gleason grade 7 adenocarcinoma of the prostate gland. Before any further workup, the patient was hospitalized at another institution 1 month later with an acute myocardial infarction. He was temporarily lost to followup.

Seven months after his original biopsy, the patient returned with similar urinary complaints as well as tenesmus and constipation. Digital rectal examination now revealed a grapelike rectal mass that obscured proper prostatic palpation. The PSA level was now $2315 \mathrm{ng} / \mathrm{mL}$.

Because of the possibility of a secondary rectal carcinoma, a gastrointestinal evaluation was per- 


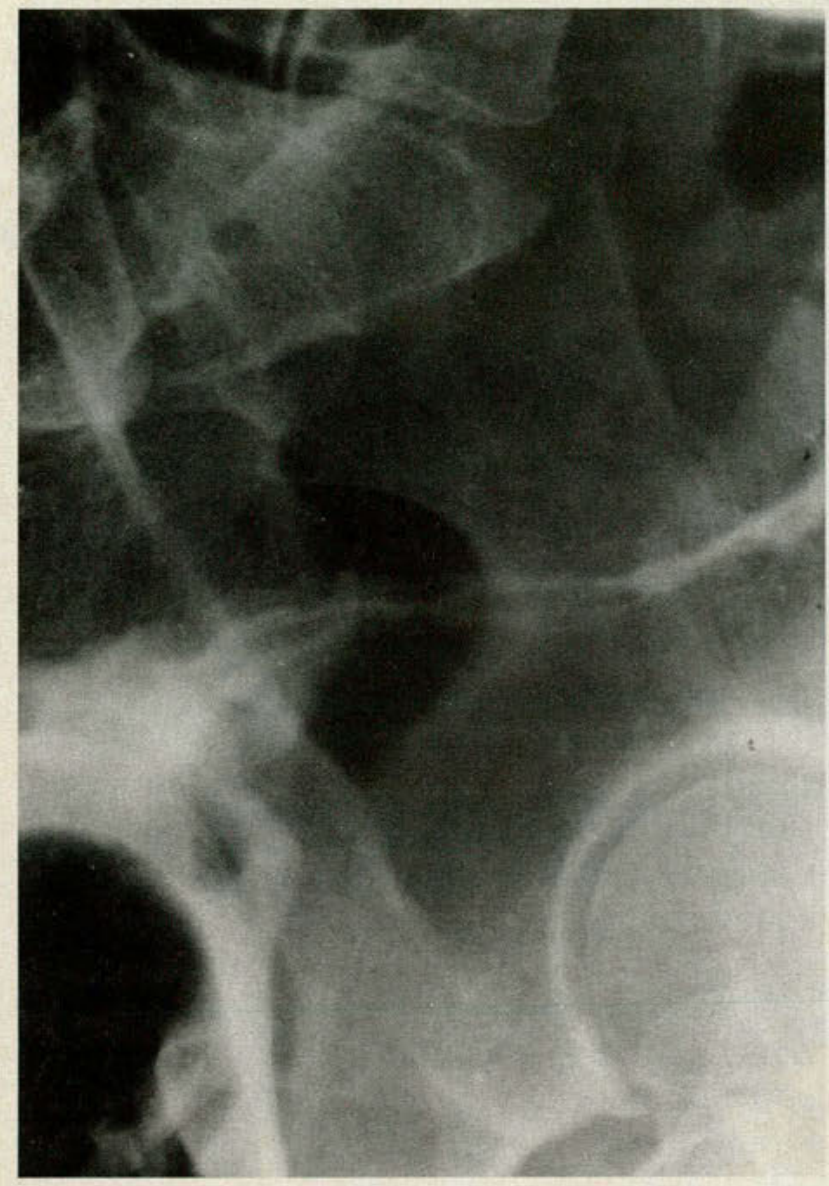

Figure 1. Lateral view from the barium enema study shows a long fusiform mass surrounding the distal rectum and rectosigmoid. The mucosa is smooth and preserved, consistent with an extrinsic, rather than an intrinsic, lesion. Note widening of the presacral space.

formed. The barium enema film revealed severe narrowing of the proximal rectum. However, the rectal mucosa did appear smooth and intact (Figs 1 and 2). Flexible sigmoidoscopy was limited because of the rectal narrowing. Biopsies of the mucosa revealed chronic inflammation without identification of any tumor.

An intravenous urogram, taken before administration of the barium enema, revealed right hydroureteronephrosis and a nonvisualized left collecting system (Fig 3) despite normal blood urea nitrogen and creatinine levels of $10 \mathrm{mg} / \mathrm{dL}$ and 0.9 $\mathrm{mg} / \mathrm{dL}$, respectively. Cystoscopy revealed a friable prostatic urethra and a tumor invading the bladder trigone and obscuring both ureteral orifices. A bone scan revealed diffuse metastasis to the ribs, spine, and right femur.

The final study, performed to rule out the possibility of a rectal carcinoma, was a magnetic resonance imaging scan (Fig 4). This study failed to

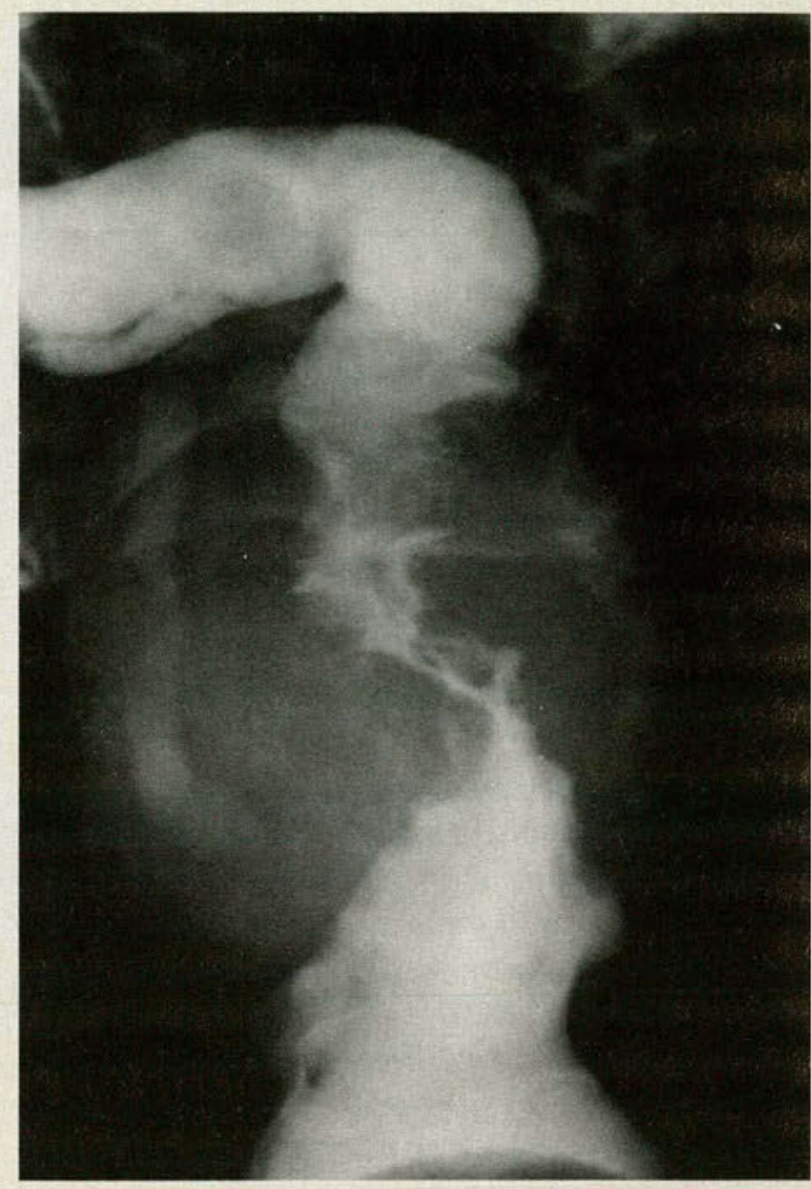

Figure 2. Anteroposterior view from the barium enema study shows intact rectal mucosa consistent with a mural, rather than a mucosal, lesion.

demonstrate any fascial planes between the prostate and the rectosigmoid region. Consequently, the rectal mass was believed to be a prostatic carcinoma with invasion.

Treatment was focused entirely on the prostatic malignancy. Bilateral nephrostomy tubes were placed to relieve the ureteral obstruction, and bilateral scrotal orchiectomy was performed for control of the primary tumor. The patient's outlet obstructive symptoms, as well as rectal and ureteral obstruction, resolved within 6 weeks of the orchiectomy. The nephrostomy tubes were subsequently removed and the patient's PSA level decreased to $120 \mathrm{ng} / \mathrm{mL}$. Two weeks after orchiectomy, the rectal mass was no longer palpable, and it was not present at the time of the patient's death 27 months after diagnosis.

\section{Discussion}

Denonvillier's fascia consists of two closely ap- 
plied layers, a periprostatic layer and a perirectal layer. ${ }^{2,4}$ The periprostatic layer is thin and can be easily invaded by prostatic carcinoma. The perirectal layer is a denser fascial structure that is more difficult to penetrate. ${ }^{2}$ Once the tumor has invaded the space between the two layers, it is easier for it to encircle the bowel than to penetrate the second, perirectal layer. ${ }^{4}$ Superior extension to the level of the seminal vesicles permits the tumor to spread laterally at this point and involve the rectosigmoid. Because cranial extension of prostatic cancer is relatively common, rectosigmoid involvement is encountered much more often than is rectal involvement.

Adenocarcinoma of the prostate may extend as far as 10 to $12 \mathrm{~cm}$ from the anal verge, directly abutting the anterior wall of the rectosigmoid junction and displacing the rectovesical space anteriorly and superiorly. Circumferential spread results in widening of the presacral space.

Rectal and rectosigmoid involvement by prostatic carcinoma are readily demonstrated by barium enema examination. This may be the initial study performed in a patient with unrecognized prostate cancer who has gastrointestinal symptoms or a rectal mass thought to represent a primary bowel neoplasm on digital rectal examination. The findings revealed by single-contrast barium enema studies have occasionally led to the erroneous diagnosis of rectal carcinoma. ${ }^{5}$

In a study using double-contrast barium enema studies, Rubesin and associates ${ }^{6}$ showed that invasive prostatic carcinoma could be differentiated from primary rectal cancer by a typical mucosal pleating or spiculation observed in the bowel wall of patients with prostate cancer invading the bowel. These findings result from an intramural desmoplastic response to a neoplastic or inflammatory process in the bowel wall and are rarely seen in patients with primary colorectal carcinoma. ${ }^{6,7}$

Three types of lower colonic involvement were described by Lazarus. ${ }^{3}$ In type I, an anterior rectal mass is present and manifests radiographically as a smooth, extrinsic mass impressing the anterior wall of the bowel. Type II involvement is the most frequently seen. It

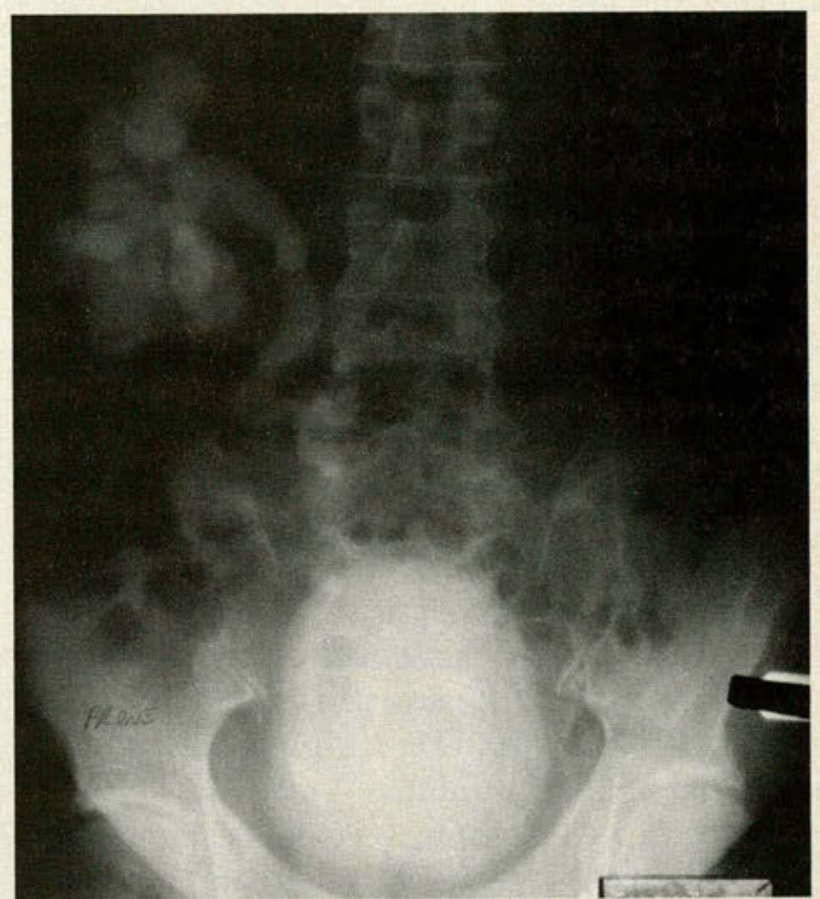

Figure 3. Intravenous urogram shows right hydroureteronephrosis and a distended urinary bladder. No visible excretion of contrast medium from the left kidney was noted.

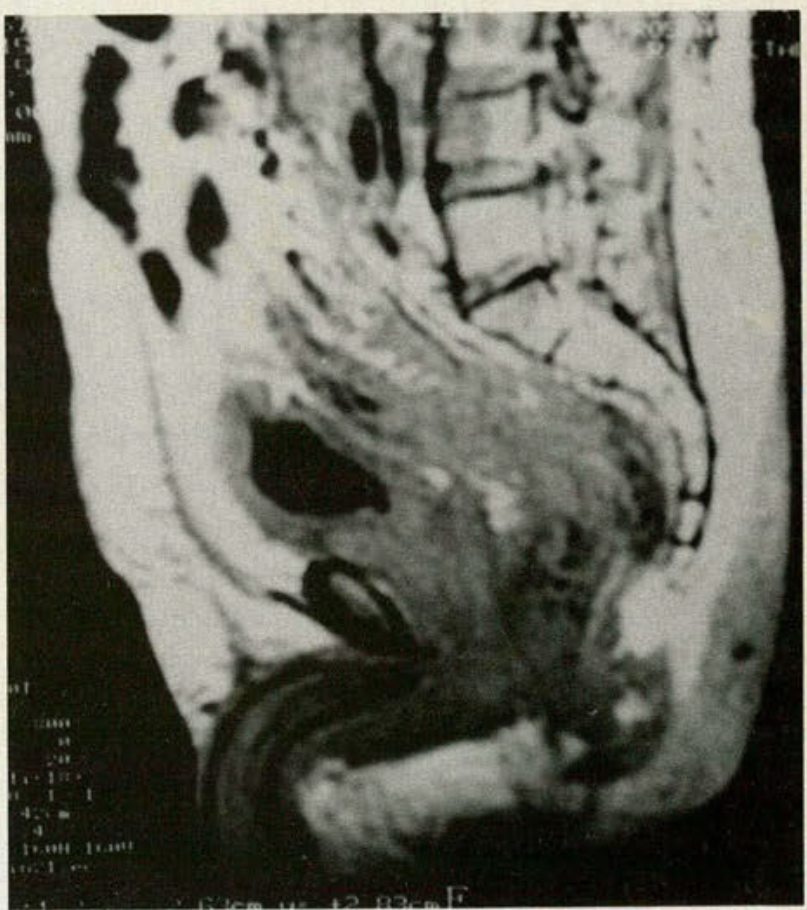

Figure 4. Sagittal view from the magnetic resonance imaging study shows the primary malignancy in the prostate and the rectal extension of the malignancy. 
appears as circumferential narrowing of the proximal rectum or rectosigmoid with associated widening of the presacral space..$^{8,9}$ This type has the radiographic appearance of an annular rectal stricture. Neither type I nor type II has mucosal involvement by the tumor. Type III involvement is the rarest of the three and consists of frank invasion of the bowel mucosa by the tumor. It appears as an anterior rectal mass with destruction or ulceration of the overlying mucosa.

Proctosigmoidoscopy can confirm the diagnosis by demonstrating mucosal integrity overlying the lesion, indicating an extrinsic process. ${ }^{10}$ Immunohistochemical stains of biopsy specimens for PSA and prostatic acid phosphatase help in differentiating poorly differentiated adenocarcinomas as prostatic in origin. ${ }^{11}$ Likewise, mucin stains help in identifying primary colorectal carcinomas. ${ }^{10}$

The differential diagnosis of rectosigmoid invasion by prostatic carcinoma includes, in addition to primary rectal carcinoma, intraperitoneal metastasis (Blumer's shelf), abscess formation in the rectovesical space, and inflammatory strictures. Prostatic carcinoma usually spreads posteriorly around the bowel, causing circumferential narrowing and widening of the presacral space. Conversely, neoplastic or inflammatory seeding of the rectovesical space almost always produces abnormalities that are confined to the anterior wall of the rectosigmoid colon. ${ }^{6}$

Other radiographic findings suggest the diagnosis of prostatic carcinoma. Many, if not most, patients with rectal involvement by prostatic carcinoma also have osteoblastic metastasis involving the axial skeleton in addition to obstructive uropathy as detected on intravenous urography or other imaging studies. ${ }^{8,10}$ Clinical features-such as symptoms of bladder outlet obstruction, bone pain, elevations in serum prostatic acid phosphatase and PSA, as well as cystoscopy-assist in establishing the diagnosis.

Treatment at this stage of the disease consists of hormonal manipulation. ${ }^{1,4}$ This therapy usually results in considerable, but temporary, improvement of both bowel and urinary tract obstruction. ${ }^{10,12}$ Transurethral re- section of the prostate may be performed for bladder outlet obstruction. ${ }^{1,4}$ Radiation therapy provides occasional relief from bowel obstruction, ${ }^{13}$ but colostomy may be required for nonresponsive or recurrent disease. ${ }^{3,14}$ Above all, recognition that the rectal lesion is prostatic in origin is essential so that appropriate therapy can be instituted.

1. Winter CC: The problem of rectal involvement by prostatic cancer. Surg Gynecol Obstet 1957;105:136-140.

2. Golfarb S, Leiter E: Invasion of the rectum by carcinoma of the prostate. Arch Surg 1980;115:1117-1119.

3. Lazarus JA: Complete rectal occlusion necessitating colostomy due to carcinoma of the prostate. Am J Surg 1935;30:502505.

4. Becker JA: Prostatic carcinoma involving the rectum and sigmoid colon. AJR 1965;94:421-428.

5. Mir D, Dikranian H, Cogbill CL: Carcinoma of the prostate presenting as obstructive carcinoma of the rectum. Am $J$ Surg 1973;39:582-586.

6. Rubesin SE, Levin MS, Bezzi M, et al: Rectal involvement by prostatic carcinoma: Barium enema findings. AJR 1989;152:53-57.

7. Meyers MA: Dynamic Radiology of the Abdomen: Normal and Pathologic Anatomy, ed 2. New York, Springer-Verlag, 1982, pp 55-92.

8. Gengler L, Baer J, Findy N: Rectal and sigmoid involvement secondary to carcinoma of the prostate. AJR 1975;125:910917.

9. Chrispin AR, Fry IK: The presacral space shown by barium enema. Br J Radiol 1963;36:319-322.

10. Fry DE, Amin M, Harbrecht PJ: Rectal obstruction secondary to carcinoma of the prostate. Ann Surg 1979;189:488-492.

11. Huang TY, Lam LT, Li CY: Unusual radiologic features of metastatic carcinoma confirmed by immunohistochemical study. Urology 1984;23:218-223.

12. Lasser A: Adenocarcinoma of the prostate involving the rectum. Dis Colon Rectum 1978;21:23-25.

13. Green N: Value of radiotherapy for adenocarcinoma of the prostate simulating primary rectal carcinoma. $J$ Urol 1974;112:247-249.

14. Shin MS, Witten DM: Unusual involvement of the rectum by carcinoma of the prostate. Am J Dig Dis 1975;20:42-48. 


\title{
Red eyes and red rash with fever: An uncommon initial presentation for staphylococcal obturator abscess with adjacent ischial osteomyelitis
}

\author{
BRUCE DAVID WHITE, DO
}

\begin{abstract}
"Red eyes and red rash with fever" is a common pediatric complaint; however, it is an uncommon initial presentation for staphylococcal obturator abscess with adjacent ischial osteomyelitis. The case of a 13-year-old boy who was admitted to the hospital with conjunctivitis, erythematous maculopapular lesions, and fever and had this final diagnosis is reported. The differential diagnosis included various bacterial diseases, several viral illnesses, and rickettsial disease.

(Key words: Conjunctivitis, erythematous maculopapular lesions, fever, scarlet fever, staphylococcal scalded skin syndrome, toxic shock syndrome, measles, atypical measles, Kawasaki syndrome, infectious mononucleosis, Rocky Mountain spotted fever, leptospirosis, ehrlichiosis, Stevens-Johnson syndrome, differential diagnosis)
\end{abstract}

Pediatric patients commonly are seen with conjunctivitis, fever, and erythematous skin lesions ("red eyes and red rash with fever"). In such cases, the physician must make logical, timely assessments that will lead to rational treatment decisions. The differential diagnosis includes some life-threatening illnesses that, if not recognized and treated properly early in the course, have fatal consequences. With such a presentation, the necessity of taking a thorough history and correlating this information with the physical findings cannot be overemphasized. The following case

From the Department of Pediatrics, Metropolitan Nashville (Tenn) General Hospital. Dr White is assistant professor of pediatrics, Meharry Medical College, Nashville.

Reprint requests to Bruce David White, DO, 194 Forestwood Dr, Nashville, TN 37209. demonstrates the complexities of making the proper diagnosis when this common triad of symptoms is present.

\section{Report of case}

A 13-year-old boy was brought to the pediatric clinic of Metropolitan Nashville General Hospital, Sept 9, 1989, with the complaints of fever, headache, malaise, rash, and vomiting. Four days before admission, he had a sore throat, low-grade fever, and tiredness developed. He took no medicines at that time. The symptoms persisted but he felt well enough to go skateboarding. Two days before admission, his temperature rose to $105^{\circ} \mathrm{F}$ and he became anorexic and extremely fatigued. He complained of pain in the back of his neck, abdomen, and left hip. On admission, he reported that he had some mild discomfort when he looked at bright lights. He had no joint pain. Acetaminophen brought only mild relief of his aches and pains.

The patient was living in a rural area. He had been in the woods often but did not recall any tick bites, although he had numerous flea bites, probably from his pet cat and dog. He did not remember traveling outside the county, but had recently been swimming in a nearby creek and lake.

The only trauma he recalled was a fall, with a bruise to his left hip sustained when skateboarding 2 days before admission. The patient thought that he had had all his childhood immunizations. $\mathrm{He}$ denied having any allergies. Admission vital signs were: temperature, $105^{\circ} \mathrm{F}$ orally; pulse, 124 beats per minute; respiratory rate, 26 per minute; blood pressure, $99 / 44 \mathrm{~mm} \mathrm{Hg}$.

On physical examination, the boy was well developed, and well-nourished but looked ill. He had mild photophobia. The bulbar and palpebral conjunctivae were moderately injected bilaterally. No scleral icterus was noted. The oropharynx was erythematous with a red strawberry tongue. No exudates were seen. The patient had circumoral pallor, with red, cracked, dry lips. The neck was supple, but the numerous, small anterior cervical 
lymph nodes were tender to palpation. Brudzinski's and Kernig's signs were negative. Heart, lung, and abdominal examination yielded normal results. No red or swollen joints were observed. The left lower extremity could be moved easily with minimal pain, but it could not be elevated past 45 degrees or adducted or abducted without marked pain.

A diffuse, generalized erythematous macular rash was present over the trunk and proximal extremities. The chest and back had some small, confluent papular lesions. Pastia's lines were seen in the antecubital fossae. All the lesions blanched with pressure. No petechiae were seen.

Admission laboratory values were as follows: hemoglobin, $13.7 \mathrm{~g} / \mathrm{dL}$; white blood cell (WBC) count, $8.3 \times 10^{3} / \mu \mathrm{L}$ with $32 \%$ band forms, $60 \%$ segmented neutrophils, and $2 \%$ lymphocytes; platelet count $205 \times 10^{3} / \mathrm{mm}^{3}$. The urine had a high specific gravity. Throat rapid streptococcal screen was negative. Erythrocyte sedimentation rate was $60 \mathrm{~mm} / \mathrm{h}$. The serum sodium level was $134 \mathrm{mmol} / \mathrm{L}$, and other blood chemistry values were normal. The findings on chest and hip x-ray films were interpreted as normal.

On admission, the patient was given intravenous fluids and oral acetaminophen. (Maximum temperature over the next 24 hours was $102^{\circ} \mathrm{F}$.) Within 12 hours, a presumptive diagnosis of Rocky Mountain spotted fever was made; intravenous chloramphenicol therapy was started at $50 \mathrm{mg} / \mathrm{kg} / \mathrm{d}$ at 6 -hour intervals. The patient began to have a nonproductive cough and chest and abdominal pain. The chest was clear to auscultation; the abdomen was diffusely tender; and the rest of the abdominal examination and rectal examination yielded normal results.

A second series of laboratory studies showed the following changes: WBC count, $4.7 \times 10^{3} / \mu \mathrm{L}$ with $34 \%$ band forms, $49 \%$ segmented neutrophils, and $7 \%$ lymphocytes; platelet count, $147 \times 10^{3} / \mathrm{mm}^{3}$. The relatively low WBC count and low-normal thrombocyte and serum sodium values persisted, as did the chest pain and vomiting. A second chest $\mathrm{x}$-ray film showed no abnormalities.

The following morning, the patient's throat was sorer and his abdomen was more tender. The back and buttocks were much more erythematous than other areas, and a few clear vesicles were seen at the patient's beltline. The SMA-18 chemistry values were normal except for serum sodium, 132 $\mathrm{mmol} / \mathrm{dL}$. The WBC and platelet counts remained unchanged. One of three blood cultures grew what appeared to be Staphylococcus. The patient continued to improve.
On the third hospital day, the patient complained of severe abdominal pain. The abdomen was diffusely tender; the liver was $3 \mathrm{~cm}$ below the costovertebral margin. The hip was more painful and the nonproductive cough, much worse. The generalized erythematous rash began to disappear. Chest and abdominal roentgenograms showed no abnormality. Two of the blood cultures grew organisms; the first organism was identified as coagulase-positive Staphylococcus aureus. Intravenous oxacillin, $100 \mathrm{mg} / \mathrm{kg} / \mathrm{d}$ at 6 -hour intervals, was prescribed. Later in the day, the patient was anxious and dyspneic, the respiratory rate was 40 per minute, the chest roentgenogram revealed hilar streaking, and arterial blood gases were normal. The patient was given $2 \mathrm{~L}$ of flow oxygen by nasal cannula. He was transferred to Vanderbilt Children's Hospital for intensive care. The respiratory discomfort resolved in transit.

Infectious disease and orthopedic consultations were obtained on arrival. Oxacillin was the only antibiotic therapy continued. On computed tomography (CT) scans of the abdomen and pelvis, the area around the patient's left obturator foramen was edematous and the internal and external obturator muscles were swollen. Hip x-ray films were unremarkable. These findings were interpreted as being consistent with an obturator abscess.

The patient remained febrile but improved clinically. An isotope bone scan on the fifth day showed increased activity in the left ischial region.

On the sixth hospital day, the patient underwent incision and drainage of the probable abscess. A $0.25-\mathrm{cm}$ cortical defect in the ischium was at the border of the external obturator muscle's origin. About $10 \mathrm{~mL}$ of gross pus welled from the lesion under manipulative pressure. Further digital exploration showed an approximately $3 \times 3-\mathrm{cm}$ pocket just anterior to the hamstring muscles' origin on the ischial tuberosity. These lesions were curetted thoroughly. Intraoperative cultures were positive for $S$ aureus.

The patient remained febrile for the next 6 postoperative days on an intravenous antibiotic regimen. Periodic bactericidal titers were adequate. After the patient showed continuous, gradual improvement, his therapy was changed to oral oxacillin on postoperative day 12 . He was discharged from the hospital on the 16th postoperative day on a regimen of dicloxacillin for 4 weeks. At discharge, he was walking with minimal pain, anteroposterior pelvic films were normal, and the erythrocyte sedimentation rate was $69 \mathrm{~mm} / \mathrm{h}$, down from 84 $\mathrm{mm} / \mathrm{h}$ on the day of transfer. 


\section{Discussion}

This case demonstrates the extremely wide differential diagnosis that must be considered for the symptoms triad of red eyes and red rash with fever. ${ }^{1}$ It also confirms an infrequent initial presentation of osteomyelitis.

The bacterial causative possibilities for these symptoms include streptococcal and staphylococcal disease (Table). Intense pharyngitis, strawberry tongue, circumoral pallor, Pastia's lines, generalized erythematous macular lesions (often "sandpapery" to touch), and a left-shift with the presence of band forms suggest scarlet fever. Staphylococcal scalded skin syndrome and toxic shock syndrome have much the same presentation. ${ }^{2}$ Portals of bacterial entry may be noted. The skin in staphylococcal diseases is usually extremely erythematous and sensitive; clear vesicular lesions are common. Nikolsky's sign may be present. Shock may result if treatment is delayed. Once the organisms are identified by culture, appropriate penicillins are curative.

The differential diagnosis includes life-threatening rickettsial disease (Table). Rocky Mountain spotted fever is usually seen in the summer. This patient, living in an endemic area, may have been exposed to ticks; what appeared to be insect bites in various stages of healing were seen during examination. Early in the course of the illness, the characteristic patient has high fever, headache, arthralgia, myalgia, and malaise with rashes of various description. Hyponatremia, leukocytopenia, and thrombocytopenia may be seen; the patient in this case had mild presentations of all three. Treatment must be initiated as soon as the diagnosis is suspected. Confirmatory titers are necessary unless biopsy of the lesions can be done with sections of the specimen appropriately stained for rapid diagnosis. Intravenous chloramphenicol is highly effective and can be used in patients who cannot tolerate oral tetracycline.

Several viral illnesses are included in the differential diagnosis (Table). Measles has a prodrome of cough, coryza, and conjunctivitis. The rash appears initially as blanching, red truncal maculopapular lesions that evolve over time in the characteristic pattern. Similarly, "atypical measles" has been seen in those chil- dren who received an "after-killed" virus via immunization. This patient had some of the symptoms of Kawasaki syndrome (circumoral pallor with strawberry tongue and red, cracked lips; rash) but lacked the diffuse lymphadenopathy necessary to the diagnosis. EpsteinBarr virus infection, the "great mimicker" of other diseases, is common in adolescents.

Two infrequently seen illnesses have presenting symptoms seen in this case. Leptospirosis is noted for intense erythroderma and meningitis. In the case reported here, the patient had been swimming in creek water, a possible source of infective agents. Gastrointestinal symptoms and liver involvement are seen in leptospiral infection. Titers are necessary to confirm its presence; penicillin is the treatment of choice. Ehrlichiosis, a disease once thought to affect only animals, has been reported in man. ${ }^{3}$ Stomatitis, various gastrointestinal symptoms, and scarlatiniform lesions have been observed along with rash, conjunctivitis, and fever. Ehrlichia canis titers confirm the diagnosis; tetracycline is the treatment of choice (Table).

In the case reported, blood cultures established staphylococcal infection. Antistaphylococcal penicillin was effective in vitro. Presumably, the patient injured the external obturator muscle when he fell while skateboarding. The resulting hematoma was probably seeded from circulating organisms that may have gained entry from the infected insect bites. An abscess thus could develop. Osteomyelitis is an infection of the bone that sometimes begins in this fashion. ${ }^{4}$ In older children, insect bites and lacerations are common portals of entry; often no entry lesion is identified. Staphylococcus aureus is the most common causative bacterium, but groups A and B streptococci are also common. ${ }^{5}$ Organisms enter the circulation and spread hematogenously, usually localizing beneath the epiphyseal plate where blood flow is slow and phagocytic activity poor.

Initial symptoms of osteomyelitis may be pain, localized swelling, and fever. Antibiotic therapy should be initiated as soon as cultures are obtained. Blood cultures are most often positive during the bacteremic phase. The most accurate means of identifying the organism is 
Table

Possible Differential Diagnoses* for 'Red Eyes and Red Rash With Fever'

\begin{tabular}{|llll|}
\hline \multicolumn{1}{|c}{ Disease } & \multicolumn{1}{c}{ Cause } & Conjunctiva & Oral cavit \\
\hline Scarlet fever & $\begin{array}{c}\text { Group A } \\
\text { streptococcus }\end{array}$ & $+/$-Hyperemia & $\begin{array}{c}\text { Pharyngiti } \\
\text { strawber }\end{array}$ \\
$\begin{array}{l}\text { Staphylococcal } \\
\text { scalded skin syndrome }\end{array}$ & $\begin{array}{c}\text { Staphylococcus aureus, } \\
\text { phage group II }\end{array}$ & Purulent & $\ldots$ \\
$\begin{array}{c}\text { Toxic shock } \\
\text { syndrome }\end{array}$ & $\begin{array}{c}\text { S aureus, phage } \\
\text { group I }\end{array}$ & Hyperemic & Erythema \\
$\begin{array}{c}\text { Rocky Mountain } \\
\text { spotted fever }\end{array}$ & Rickettsia rickettsii & Hyperemic & Erythema \\
\hline
\end{tabular}

$\begin{array}{llll}\text { Measles } & \text { Rubeola virus } & \text { Purulent } & \text { Koplik's spot } \\ \begin{array}{l}\text { Atypical } \\ \text { measles }\end{array} & \begin{array}{c}\text { "After-killed" } \\ \text { rubeola virus }\end{array} & \text { Hyperemic } & \ldots \\ \begin{array}{c}\text { Kawasaki } \\ \text { syndrome }\end{array} & \text { Viral (?) } & \text { Hyperemic } & \begin{array}{c}\text { Cracked lips, } \\ \text { erythema }\end{array}\end{array}$

$\begin{array}{llll}\begin{array}{l}\text { Infectious } \\ \text { mononucleosis }\end{array} & \text { Epstein-Barr virus } & +/- \text { Hyperemia } & \text { Exudative pharyngitis } \\ \text { Leptospirosis } & \text { Leptospira } & \text { Hyperemic } & +/- \text { Erythema }\end{array}$

$\begin{array}{lll}\text { Erlichiosis Erlichia canis Hyperemic Stomatitis } & \text { Hy }\end{array}$

$\begin{array}{llll}\begin{array}{c}\text { Stevens-Johnson } \\ \text { syndrome }\end{array} & \begin{array}{c}\text { Drugs, infectious } \\ \text { organisms }\end{array} & +/- \text { Hyperemia } & \text { Ulcers }\end{array}$

*Not intended as an exhaustive list.

intraoperative culture. Early x-ray films are often normal, with bony changes usually becoming evident in 10 to 14 days. Bone scans show areas of increased activity earlier than plain radiographs. Early treatment with effective antibiotics and operative intervention, if necessary, usually leads to complete resolution.

With this presentation, the presumptive diagnosis of Rocky Mountain spotted fever was warranted. ${ }^{6}$ Early initiation of therapy when this diagnosis cannot be eliminated from the differential diagnosis is essential. Given the fact that chloramphenicol has antistaphylococcal activity, the use of that single drug could be justified as empiric therapy awaiting cultures. (In the case reported, the organism proved sensitive to chloramphenicol in vitro.) The patient's symptoms also strongly sug- 


\begin{tabular}{|c|c|c|c|}
\hline \multicolumn{4}{|c|}{$\begin{array}{l}\text { Table (continued) } \\
\text { Possible Differential Diagnoses* for 'Red Eyes and Red Rash With Fever' }\end{array}$} \\
\hline Disease & Exanthem & Other findings & Therapy \\
\hline Scarlet fever & $\begin{array}{l}\text { Diffuse, "sand- } \\
\text { papery" lesions, } \\
\text { Pastia's lines }\end{array}$ & $\begin{array}{l}\text { Rheumatic fever, } \\
\text { glomerulonephritis }\end{array}$ & Penicillin \\
\hline $\begin{array}{l}\text { Staphylococcal } \\
\text { scalded skin syndrome }\end{array}$ & $\begin{array}{l}\text { Painful erythro- } \\
\text { derma, Nikolsky's } \\
\text { sign }\end{array}$ & Septicemia & $\begin{array}{l}\text { Antistaphylococcal } \\
\text { penicillin }\end{array}$ \\
\hline $\begin{array}{r}\text { Toxic shock } \\
\text { syndrome }\end{array}$ & Erythroderma & $\begin{array}{l}\text { Shock, multiple } \\
\text { organ failure }\end{array}$ & $\begin{array}{l}\text { Antistaphylococcal } \\
\text { penicillin }\end{array}$ \\
\hline $\begin{array}{l}\text { Rocky Mountain } \\
\text { spotted fever }\end{array}$ & $\begin{array}{l}\text { Maculopapular } \\
\text { lesions, } \\
\text { petechiae }\end{array}$ & $\begin{array}{l}\text { Arthralgia, myalgia, } \\
\text { syndrome of } \\
\text { inappropriate } \\
\text { antidiuretic } \\
\text { hormone }\end{array}$ & Chloramphenicol \\
\hline Measles & $\begin{array}{l}\text { Morbilliform } \\
\text { lesions }\end{array}$ & Coryza, cough & $\ldots$ \\
\hline $\begin{array}{l}\text { Atypical } \\
\text { measles }\end{array}$ & $\begin{array}{l}\text { Central "measles- } \\
\text { like" lesions, } \\
\text { petechiae }\end{array}$ & Pneumonia & ... \\
\hline $\begin{array}{l}\text { Kawasaki } \\
\text { syndrome }\end{array}$ & $\begin{array}{l}\text { Polymorphous } \\
\text { erythema }\end{array}$ & $\begin{array}{l}\text { Prolonged high } \\
\text { fever on anti- } \\
\text { biotics, enlarged } \\
\text { lymph nodes, } \\
\text { "puffy hands, feet" }\end{array}$ & $\begin{array}{l}\text { Aspirin, gamma } \\
\text { globulin }\end{array}$ \\
\hline $\begin{array}{l}\text { Infectious } \\
\text { mononucleosis }\end{array}$ & $\begin{array}{l}\text { Varied maculo- } \\
\text { papular lesions }\end{array}$ & Splenomegaly & $\ldots$ \\
\hline Leptospirosis & Erythroderma & $\begin{array}{l}\text { Cholangitis, } \\
\text { meningitis }\end{array}$ & Penicillin \\
\hline Ehrlichiosis & $\begin{array}{l}\text { Scarlatiniform } \\
\text { lesions }\end{array}$ & $\begin{array}{l}\text { Gastrointestinal } \\
\text { distress }\end{array}$ & Tetracycline \\
\hline $\begin{array}{l}\text { Stevens-Johnson } \\
\text { syndrome }\end{array}$ & Erythema multiforme & $\begin{array}{l}\text { Mucous membrane } \\
\text { ulcerations, } \\
\text { skin sloughing }\end{array}$ & Steroids (?) \\
\hline${ }^{*}$ Not intended as an exhaustive list. & & & \\
\hline
\end{tabular}

gested the possibility of streptococcal, staphylococcal, other rickettsial diseases, leptospirosis, and ehrlichiosis.

\section{Conclusion}

A logical approach to the diagnosis of an adolescent who has the common triad of red eyes and red rash with fever is given. The uncommon finding of staphylococcal obturator ab- scess with adjacent ischial osteomyelitis (with near-toxic shock symptoms) illustrates the need for beginning with the broadest possible list of differential diagnoses. The importance of continually reevaluating the patient's progress in light of this differential diagnosis to decrease morbidity and mortality from potentially treatable ailments is emphasized by this case. 
The assistance of the following colleagues at Metropolitan Nashville General Hospital is gratefully acknowledged: William A. Altemeier III, MD, and David W. Gregory, MD, Vanderbilt University, and Suzanne Snyder, MD, formerly at Metropolitan General Hospital. The Table is adapted from unpublished material prepared for a 1987-1988 infectious disease residents' conference by Gerard B. Rabalais, MD, University of Louisville School of Medicine, Kentucky.

1. Moffet HL: Pediatric Infectious Disease: A Problem-Oriented Approach, ed 3. Philadelphia, JB Lippincott Co, 1989, pp 307320.

2. Reingold AL, Hargett NT, Dan BB, et al: Non-menstrual toxic shock syndrome. Ann Intern Med 1982;96:871-874.

3. McDade JE: Ehrlichiosis-a disease of animals and humans. $J$ Infect Dis 1990;161:609-617.

4. Avery ME, First LR: Pediatric Medicine. Baltimore, William \& Wilkins, 1989, p 1289-1291.

5. American Academy of Pediatrics: Report of the Committee on Infectious Diseases. Elk Grove Village, Ill, American Academy of Pediatrics, 1986, p 486.

6. Donowitz LG: Rickettsial disease, in Nelson JD: Current Therapy in Pediatric Infectious Disease. Toronto, BC Decker Inc, 1986, pp 184-187. 


\title{
Axillary disruption of axillobifemoral graft
}

\author{
THOMAS W. WEHMANN, DO
}

VAL A. RONGAUS, DO

Axillary disruption of axillobifemoral grafts has not previously been reported after appropriate placement of the graft medially on the axillary artery and proper subpectoral tunneling. Six weeks after undergoing such surgery followed by a relatively uncomplicated postoperative course, the patient-an 81-yearold man-was found unconscious at home. He was resuscitated, and taken to an emergency room where he had a respiratory arrest. At surgery, it was found that the polytetrafluoroethylene graft had separated from the axillary artery. Inspection of the axillary artery showed a completely intact suture line on the artery itself. Graft cultures tested negative. The authors believe the anastomotic disruption was the result of trauma to the anastomosis during cardiopulmonary resuscitation and external cardiac massage.

(Key words: Axillobifemoral graft, axillary artery, graft, bypass)

Since the introduction by Blaisdell and Hall $^{1}$ of the axillary-femoral artery bypass for lower extremity ischemia in 1962, there have been remarkably few complications reported. Most serious complications are related to graft thrombosis. ${ }^{2,3}$ However, hematoma, kinking, inadequate outflow, false aneurysm, embolization, brachial plexus injury, subclavian and axillary artery occlusion, and arterial steal syndrome ${ }^{4}$ have been reported.

From the Department of General Surgery, Cuyahoga Falls General Hospital, Cuyahoga Falls, Ohio, where, at the time this article was written, Dr Wehmann was a resident in general surgery, and where Dr Rongaus is chief of surgery. Dr Wehmann is now a vascular and general surgeon, Cuyahoga Falls General Hospital.

Reprint requests to Thomas W. Wehmann, DO, Falls Surgical Group, 1900 23rd St, Cuyahoga Falls, OH 44223 .
Many articles have described the method of distal anastomosis and include the "lazy S," "inverted C," low crossover with a short ipsilateral limb, and anastomosis to the common femoral artery. ${ }^{5}$ Details of the proximal anastomosis have been less well elucidated, although even Blaisdell and $\mathrm{Hall}^{6}$ originally recommended formation of the proximal anastomosis lateral to the pectoralis minor muscle and at the inferior border of the longitudinally opened artery.

Sauvage ${ }^{7}$ stated that the most important point in proper positioning is to position the anastomosis as far medially as possible to minimize the tension on the anastomosis with arm abduction. If the pectoralis minor tendon is in the way, the anastomosis is placed too far distally on the axillary artery. Bunt and Moore ${ }^{8}$ further emphasized the importance of proper placement of the proximal anastomosis and of the tunnel. The subpectoralis position appears to be the one favored for the tunnel.

There have been reports of disruption of the proximal anastomosis in two patients in whom the anastomosis was improperly placed. ${ }^{9}$ Both occurred with abduction of the arm approximately 6 weeks after surgery. We report disruption of the proximal anastomosis in an 81year-old man in whom the anastomosis and graft tunnel were properly placed. The disruption occurred 6 weeks postoperatively after transport by paramedics and cardiopulmonary resuscitation for cardiopulmonary arrest caused by acute myocardial infarction.

\section{Report of case}

The patient, a pipe smoker, was seen with progressive claudication in both legs of 2 years' duration. This condition would occur after he had walked half a block, and it interfered significantly with his desired lifestyle. The patient had no known major health problems other than systemic hypertension easily controlled by diet and antihypertensive agents. 


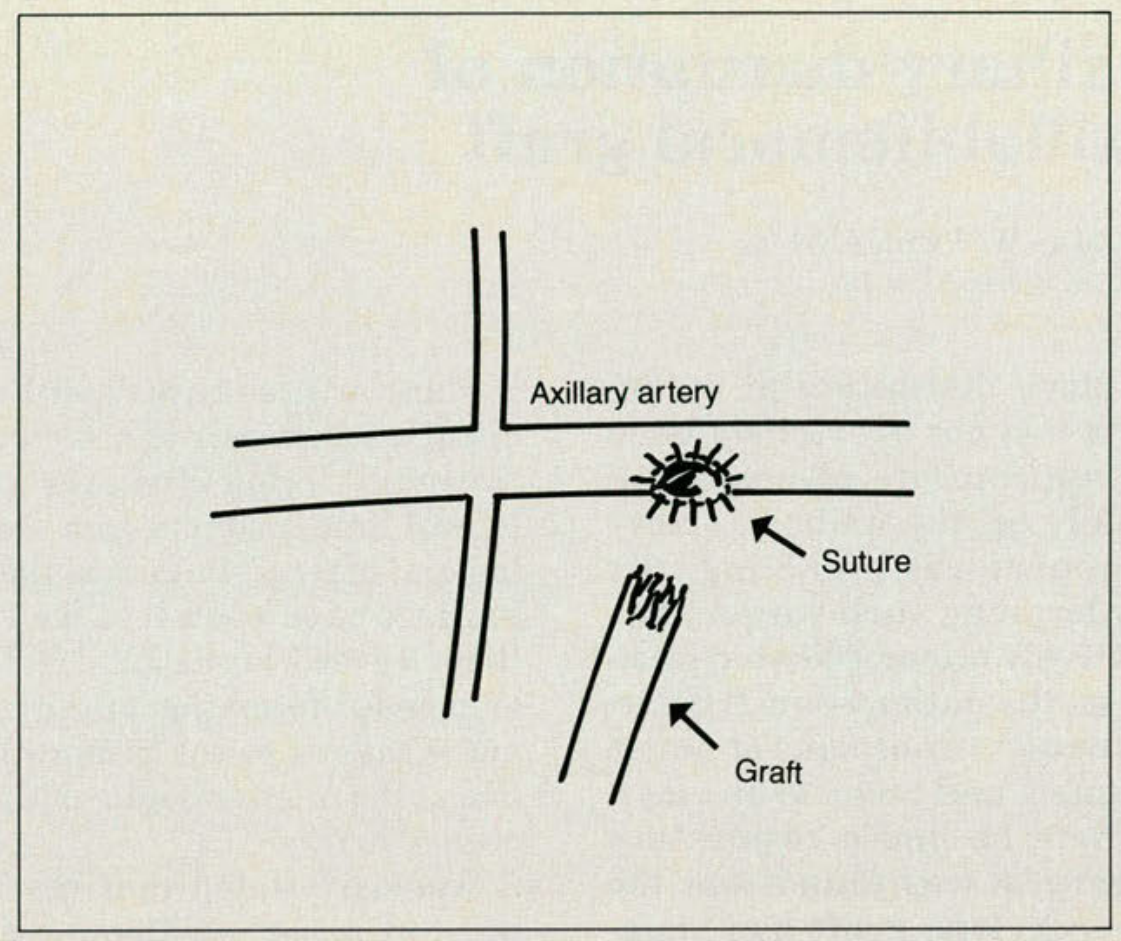

Figure. Illustration demonstrating disruption of polytetrafluoroethylene graft from axillary artery with intact suture line.

Arteriograms revealed severe atheromatous disease in the pararenal aorta. Both the common and external iliac arteries were severely diseased with a near-complete occlusion of the left external iliac artery and an estimated $80 \%$ stenosis of the right. The patient appeared to have adequate deep femoral arteries for anastomosis to the common femoral arteries bilaterally and one vessel runoff in the infrapopliteal regions. In June 1989, he underwent a left axillobifemoral bypass procedure in which an 8-mm-diameter, ringed, thin-walled polytetrafluoroethylene (PTFE) prosthetic graft was placed. The proximal anastomosis was placed medial to the tendon of the pectoralis minor muscle and tunneled subcutaneously from a subpectoral position.

The patient's postoperative course was uncomplicated except for an episode of urinary retention and some mild numbness of the long, ring, and little fingers of the left hand. This numbness was believed to be caused by intraoperative brachial plexus traction or compression. An office examination the following month showed no claudication symptoms, good healing of incisions, and continued mild numbness of the fingers with normal muscular activity.

Six weeks after graft placement, the patient's wife found him unconscious on the bedroom floor. Whether the patient fell or had a cardiac dysfunction is not known. He was resuscitated by para- medics, and taken to the emergency room where he had a respiratory arrest and was intubated.

Initial laboratory tests disclosed the following values: hemoglobin, $10.5 \mathrm{~g} / \mathrm{dL}$; hemocrit, $33 \%$; serum potassium, $2.8 \mathrm{mmol} / \mathrm{L}$; serum sodium, 146 $\mathrm{mmol} / \mathrm{L}$; blood urea nitrogen, $30 \mathrm{mg} / \mathrm{L}$; lactic acid level, $176 \mathrm{mmol} / \mathrm{L}$; platelets, $275,000 / \mathrm{mm}^{3}$; creatine phosphokinase (CPK), $940 \mathrm{mU} / \mathrm{L}$; lactate dehydrogenase, $771 \mathrm{mU} / \mathrm{L}$; and serum glutamic oxaloacetic transaminase, $145 \mathrm{mU} / \mathrm{L}$. On examination in the emergency room, the patient's left anterior chest wall was found to be edematous. He was in sinus tachycardia with an $\mathrm{S}_{4}$ gallop; bilateral femoral pulses were intact.

When the patient was transferred to the intensive care unit, it was observed that the left infraclavicular region was expanded and his hemoglobin level had fallen to $5.3 \mathrm{~g} / \mathrm{dL}$, with a hematocrit of $16 \%$. Also noted was a prothrombin time of 15 seconds, a partial thromboplastin time of 38 seconds, a fibrinogen level of $12 \mu \mathrm{mol} / \mathrm{L}$, and fibrin split products greater than 40 . The myocardial band fraction of CPK was elevated. Coagulation factors were replaced and the patient was taken to surgery.

When the incision was opened, heavy arterial bleeding was encountered. Proximal control was obtained by an incision placed in the supraclavicular region and digital compression of the subclavian 
artery. It was then observed that the PTFE graft had completely separated from the axillary artery and was distracted by approximately 2.5 to $3.0 \mathrm{~cm}$. No retrograde bleeding was coming from the graft. The polypropylene suture line in the arterial wall was intact, and it appeared that the PTFE material had actually torn away from the suture line. The edge of the PTFE graft was severely frayed and there was no evidence of suppuration.

The artery was successfully repaired with polypropylene suture. A portion of graft was submitted for culture and histopathologic section. Postoperatively, left ventricular heart failure developed secondary to myocardial infarction with a significantly elevated myocardial band fraction of CPK, acute renal failure, and then multisystem organ failure. He died on July 30 . The graft culture was found to be negative.

\section{Discussion}

Previous reports have described axillary disruption of axillofemoral grafts when anastomosis was placed too far laterally on the axillary artery. It appears that abduction of the arm in these cases accounted for undue tension on the anastomosis with resultant tearing and hemorrhage, as has been reported by Sullivan and colleagues. ${ }^{9}$ It also appears that improper subcutaneous tunnel placement can contribute to disruption.

Axillary disruption of axillobifemoral grafts has not previously been reported with appropriate placement of the graft medially on the axillary artery and proper subpectoral tunneling. We initially believed that infection may have contributed to graft disruption; however, cultures were negative. We then suspected that the anastomosis was flawed, but inspection of the axillary artery at surgery showed a completely intact suture line on the artery itself, as demonstrated in the Figure.

We believe that this anastomotic disruption was the result of trauma to the anastomosis during cardiopulmonary resuscitation and external cardiac massage by compression of the thoracic cage. This motion would effectively cause a tearing action at the anastomosis, even with medial placement of the anastomosis on the axillary artery. It is also possible that the anastomosis was disrupted when the patient was lifted by the paramedics from the bedroom floor where he probably fell because of a cardiac dysrhythmia.

Multiple complications have been reported from the life-saving maneuvers associated with cardiopulmonary resuscitation and are well documented in the literature. It appears that axillary graft disruption may need to be added to this list.

The important point to be gained from this report is that extra-anatomic bypass ${ }^{10}$ is just that-extra-anatomic. Normal blood vessel anatomy is oriented to prevent injury to these important structures. When the surgeon decides to use extra-anatomic procedures, he must be aware that normal protective mechanisms are bypassed, subjecting the patient to risks not normally present when anatomic procedures are used. Strict adherence to the indications for extra-anatomic bypass are essential in preventing complications that may be life-threatening.

1. Blaisdell FW, Hall AD: Axillary-femoral artery bypass for lower extremity ischemia. Surgery 1963;54:563-568.

2. Mannick JA, Williams LE, Nasbeth DC: The late results of axillofemoral grafts. Surgery 1970;68:1038-1043.

3. Parsonnet V, Alpert J, Brief DK: Femorofemoral and axillofemoral grafts: Compromise or preference. Surgery 1970;67:2633.

4. Kempczinski R, Penn I: Upper extremity complications of axillofemoral grafts. Am J Surg 1978;136:209-211.

5. Rutherford RB: Vascular Surgery, ed 3. Philadelphia, WB Saunders Co, 1989, p 711.

6. Blaisdell FW, Hall AD: Axillary-femoral artery bypass for lower extremity ischemia. Surgery 1963;54:563-568.

7. Sauvage LR: Unilateral axillary bilateral femoral bifurcation graft: A procedure for the poor risk patient with aortoiliac disease. Surgery 1966;60:573-577.

8. Bunt TJ, Moore W: Optimal proximal anastomosis/tunnel for axillofemoral grafts. J Vasc Surg 1986;3:673-676.

9. Sullivan LP, Davidson PG, D'Anna JA Jr, et al: Disruption of the proximal anastomosis of axillobifemoral grafts: Two case reports. J Vas Surg 1989;10:190-192.

10. Blaisdell FW: Extraanatomical bypass. Contemp Surg 1984;25:109-151. 